\title{
The tetraspanins CD151 and Tspan8 are essential exosome components for the crosstalk between cancer initiating cells and their surrounding
}

\author{
Shijing Yue ${ }^{1, *}$, Wei Mur ${ }^{1, *}$, Ulrike Erb ${ }^{1}$ and Margot Zöller ${ }^{1}$ \\ ${ }^{1}$ Department of Tumor Cell Biology, University Hospital of Surgery, Heidelberg, Germany \\ * These authors contributed equally to this work \\ Correspondence to: Margot Zöller, email: m.zoeller@uni-hd.de \\ Keywords: Tetraspanins, exosomes, metastasis, matrix degradation, EMT \\ Received: October 17, $2014 \quad$ Accepted: December 09, $2014 \quad$ Published: December 10, 2014 \\ This is an open-access article distributed under the terms of the Creative Commons Attribution License, which permits unrestricted use, \\ distribution, and reproduction in any medium, provided the original author and source are credited.
}

\section{ABSTRACT}

Tspan8 and CD151 are metastasis-promoting tetraspanins and a knockdown (kd) of Tspan8 or CD151 and most pronounced of both tetraspanins affects the metastatic potential of the rat pancreatic adenocarcinoma line ASML. Approaching to elaborate the underlying mechanism, we compared ASMLt, $-C D 151^{\mathrm{kd}}$ and/or Tspan ${ }^{\mathrm{kd}}$ clones. We focused on tumor exosomes, as exosomes play a major role in tumor progression and tetraspanins are suggested to be engaged in exosome targeting.

ASML-CD151/Tspan8 ${ }^{\mathrm{kd}}$ cells poorly metastasize, but regain metastatic capacity, when rats are pretreated with ASMLwt, but not ASML-CD151 ${ }^{\mathrm{kd}}$ and/or - Tspan8 ${ }^{\mathrm{kd}}$ exosomes. Both exosomal CD151 and Tspan8 contribute to host matrix remodelling due to exosomal tetraspanin-integrin and tetraspanin-protease associations. ASMLwt exosomes also support stroma cell activation with upregulation of cytokines, cytokine receptors and proteases and promote inflammatory cytokine expression in hematopoietic cells. Finally, CD151-/Tspan8-competent exosomes support EMT gene expression in poorly-metastatic ASML-CD151/Tspan8 ${ }^{\mathrm{kd}}$ cells. These effects are not seen or are weakened using ASML-CD151 ${ }^{\mathrm{kd}}$ or - Tspan $8^{\mathrm{kd}}$ exosomes, which is at least partly due to reduced binding/uptake of CD151- and/or Tspan8-deficient exosomes.

Thus, CD151- and Tspan8-competent tumor exosomes support matrix degradation, reprogram stroma and hematopoietic cells and drive non-metastatic ASML-CD151/Tspan8kd cells towards a motile phenotype.

\section{INTRODUCTION}

Tumors are a heterogeneous mixture of cells, where a small population of so called cancer-initiating cells (CIC) [1,2] is supposed to account for tumor progression including epithelial-mesenchymal transition (EMT) and metastatic settlement and growth [3.4]. With the description of the phenomenon of a premetastatic niche [5] the question arose on the factors that modulate selected distant organs to facilitate disseminated tumor cell embedding [6]. Similar, in concern on the shift towards EMT, the question remains to be answered, why preferentially cells at the tumor rim become engaged and which trigger they receive $[7,8]$. Particularly for the establishment of a premetastatic niche strong evidence is accumulating that exosomes are the major actors [9-11].

Exosomes, $40-100 \mathrm{~nm}$ membrane vesicles of endocytic origin [12], are secreted by many cell types, and abundantly by tumor cells [13]. Exosomes are suggested to be the most important intercellular communicators $[14,15]$. They are defined by size, buoyant density, lipid composition, and protein markers [16]. Their homogeneous size is a major criterion to differentiate from size-variable apoptotic blebs, microparticles and microvesicles [17]. Exosomes are also characterized by a panel of constitutive markers [18], which relate to their origin from endocytosis / early endosomes and include, beside others, components of endocytosis prone membrane domains and of the fission, scission and vesicular transport machineries [19]. One type of endocytosis 
prone membrane microdomains, tetraspanin-enriched microdomains (TEM) [20], apparently play a major role, as tetraspanins are most widely used to characterize extracellular vesicles as exosomes [21,22]. Furthermore, the net which tetraspanins form between themselves and a multitude of associating molecules is maintained during internalization and intracellular traffic such that tetraspanin webs are recovered in exosomes [23,24]. This feature becomes of particular interest for tetraspanins that are engaged in metastasis formation, which is well known for CD151 and Tspan8 [25,26], the latter also being a CIC marker in pancreatic adenocarcinoma [27]. It is essential to mention that exosomes also contain mRNA and miRNA $[16,28]$ and that all components of exosomes, lipids, proteins, mRNA and miRNA are function competent [29]. Furthermore, exosomes are found in all body fluids $[30,31]$ and can bind to or be taken up by selected target cells, where exosomal tetraspanin webs are involved in target cell selection [32].

Tetraspanins, a family of 4-transmembrane proteins [33], act as "molecular facilitators" modulating, stabilizing or preventing activities of associated molecules [34]. They promote spreading, migration and cable formation by adjusting integrin compartmentalization, internalization, recycling and signaling [35]. By modulating biosynthesis and activation of associated molecules, like MMPs, they influence invasiveness [36]. Though these activities are generally fitting a contribution to tumor progression, only CD151 and Tspan8 were described as metastasis-promoting in several tumor systems, with no opposing findings reported so far [25,26,37-40]. CD151 preferentially associates with laminin (LN)-binding integrins [41,42], which supports migration via integrin trafficking and activation by Ras, Rac1 and Cdc42 recruitment [43-45]. CD151 also regulates cell motility via proteases [46]. CD151 induces MMP9 expression via CD151-associated integrin signaling [47] and anchors MMP7 at the cell membrane by MMP9 binding [48]. CD151 also associates with MMP14 [49] and regulates ADAM10 and ADAM17 activity by recruitment into TEM [46]. Finally, a cathepsinB or UPAR knockdown inhibits CD151- $\alpha 3 \beta 1-$ mediated cell adhesion and invasion [50]. Finally, a CD151 molecule with a mutation of the sorting motif in the C-terminal domain markedly attenuates endocytosis of CD151-associated $\alpha 3 \beta 1, \alpha 5 \beta 1$ and $\alpha 6 \beta 1$ $[36,43]$, which could affect CD151-supported exosome activity.

We recently uncovered by a CD151 knockdown $\left(\mathrm{CD} 151^{\mathrm{kd}}\right)$ in a rat pancreatic adenocarcinoma that CD151 promotes adhesion, which is overcome by CD151associated MMPs degrading the extracellular matrix [51]. Tspan 8 by associating with $\alpha 6 \beta 4$ [52,53] contributes to paxillin and FAK activation and supports motility [51]. Accordingly, both ASML-CD $151^{\mathrm{kd}}$ and ASMLTspan $8^{\mathrm{kd}}$ cells displayed reduced metastatic capacity, the deficits suggesting supplementary activities of the two tetraspanins. To substantiate this assumption, we generated double ASML-CD151/Tspan8 ${ }^{\mathrm{kd}}$ clones, which poorly metastasize. Based on this finding, the known contribution of exosomes to the metastatic process [9-11] and the functional importance of exosomal tetraspanins [25], we controlled for the contribution of exosomal CD151 and Tspan8 in tumor progression. ASML-CD151/Tspan $8^{\mathrm{kd}}$ exosomes do not support metastatic settlement, they have severe defects in extracellular matrix (ECM) degradation, poorly stimulate chemokine and chemokine receptor expression and are not generating an inflammatory milieu. Finally, only ASML ${ }^{\text {wt }}$ exosomes support EMT in poorly metastatic ASML-CD151/Tspan8 ${ }^{\mathrm{kd}}$ cells.

\section{RESULTS}

We recently described that CD151 and Tspan8 distinctly, but supplementarily support metastasis, where Tspan8 predominantly accounts for motility and CD151 for adhesion and matrix degradation [51]. We here evaluate the contribution of exosomal tetraspanins to tumor progression, using as additional control an ASMLCD151/Tspan $8^{\mathrm{kd}}$ line.

\section{A CD151 / Tspan8 knockdown is accompanied by loss in metastatic tumor growth.}

ASML-Tspan $8^{\mathrm{kd}}$ cells were transfected with CD151 shRNA, selecting clones 16 and 24 for further studies (Figure 1A). After intrafootpad (ifp) application, the double knockdown clones hardly grew in draining nodes and only 1 of 5 rats developed lung metastasis. As described [51], the survival time of rats receiving ASMLCD $151^{\mathrm{kd}}$ or ASML-Tspan8 ${ }^{\mathrm{kd}}$ cells was prolonged and the tumor burden in LN and lung was reduced compared to ASML ${ }^{\text {wt }}$-bearing rats, but did not differ between ASMLCD151 $1^{\mathrm{kd}}$ - versus ASML-Tspan $8^{\mathrm{kd}}$-bearing rats. Instead, the survival time and the metastatic burden of ASML-CD151/ Tspan $8^{\mathrm{kd}}$ bearing rats differed significantly from that of ASML-CD $151^{\mathrm{kd}}$ or -Tspan $8^{\mathrm{kd}}$ bearing animals (Fig.1B1E). Lymph nodes (LN) and lung of the one rat developing lung metastasis after receiving ASML-CD151/Tspan $8^{\mathrm{kd}}$ cells displayed weak CD151 expression that, however, did not exceed the level of normal lung tissue (Fig.1F). Immunohistology staining for CD44v6, which is highly expressed in ASML cells, confirmed the stability of the Tspan $8^{\mathrm{kd}}$ and/or CD151 ${ }^{\mathrm{kd}}$ in vivo (Suppl.Fig.1).

In vitro analysis of ASML-CD151/Tspan $8^{\mathrm{kd}}$ cells as compared to $-\mathrm{Tspan} 8^{\mathrm{kd}}$ or $-\mathrm{CD} 151^{\mathrm{kd}}$ cells showed significantly decreased cloning efficacy (Suppl. Fig.2A). In vitro wound healing (data not shown) and videomicroscopy revealed unaltered motility of ASMLCD151/Tspan $8^{\mathrm{kd}}$ cells compared to that of ASML ${ }^{\text {wt }}$ cells, i.e. the opposing activities of CD151 (inhibiting) and Tspan8 (promoting) were waved (Suppl.Fig.2B). The 
reduced capacity of ASML-CD151 kd and ASML-Tspan $8^{\mathrm{kd}}$ cells to invade matrigel is further impaired in ASMLCD151/Tspan $8^{\mathrm{kd}}$ cells, which completely lost invasiveness (Suppl.Fig.2C). Finally, ASML-Tspan $8^{\mathrm{kd}}$ and ASMLCD151/Tspan ${ }^{\mathrm{kd}}$ cells poorly transmigrate through an endothelial monolayer (Suppl.Fig.2D).

Taken together, the major contribution of cellular CD151 and Tspan8 to lymphatic metastasis formation relies on promoting motility (Tspan8) and invasiveness (CD151 and Tspan8), such that ASML-CD151/Tspan8 ${ }^{\mathrm{kd}}$ cells hardly metastasize. As metastasis formation requires a crosstalk with the host [4], which is suggested to be initiated via exosomes [14,15], we proceeded controlling activities of ASML-CD151 ${ }^{\mathrm{kd}}$, ASML-Tspan $8^{\mathrm{kd}}$ and ASMLCD151/Tspan8 ${ }^{\mathrm{kd}}$ versus ASML ${ }^{\mathrm{wt}}$ exosomes.

\section{Exosomal CD151 and Tspan8 support metastatic settlement}

$\mathrm{ASML}^{\mathrm{wt}}$ exosomes are recovered in all lymphoid organs $48 \mathrm{~h}$ after intravenous (iv) application. Recovery of ASML-CD $151^{\mathrm{kd}}$ exosomes is only reduced in LN. Recovery of ASML-Tspan $8^{\mathrm{kd}}$ and -CD151/Tspan $8^{\mathrm{kd}}$


lung miliary

閶 lung $<100$

$\square$ lung neg

- $\mathrm{LNC}>1 \mathrm{~cm}$

湆 $\mathrm{LNC}<1 \mathrm{~cm}$

$\square$ LNC neg

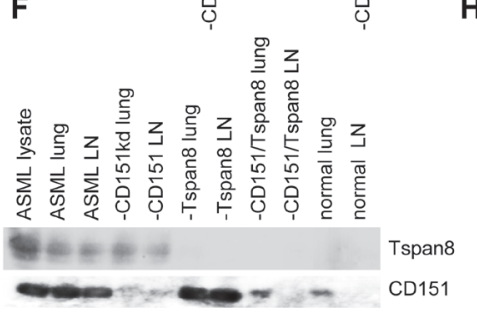

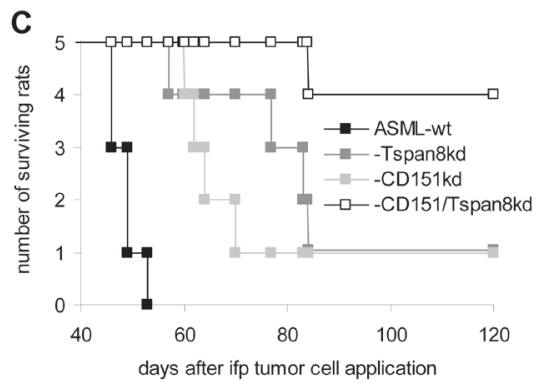

G

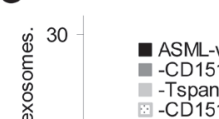

dye-labeled exosomes iv, $1 \mathrm{x}$

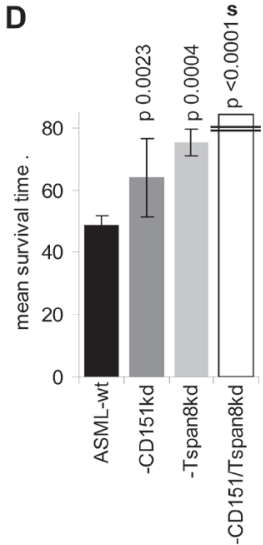

Figure 1: CD151 and Tspan8 requirement for metastasis formation and for exosome distribution. (A) WB of $A S M L$ wt cells and ASML-CD151/Tspan $8^{\mathrm{kd}}$ clones. Clones 16 and 24 were used for further experiments. (B-F) BDX rats (5/group) received an ifp injection of $1 \times 10^{6} \mathrm{ASML}^{\mathrm{wt}}$ or $-\mathrm{CD} 151^{\mathrm{kd}}$ and/or $-\mathrm{Tspan} 8^{\mathrm{kd}}$ cells. (B) Tumor growth in the popliteal node; (C) survival time and survival rate; (D) mean survival time, indicating significant differences compared to ASML ${ }^{\text {wt }}$-bearing rats and between ASML-CD151/Tspan8 ${ }^{\mathrm{kd}}$ versus $-\mathrm{CD} 151^{\mathrm{kd}}$ or Tpsan $8^{\mathrm{kd}}$ bearing rats: s; (E) No of rats with small or large LN metastasis and of rats with no, few or $>1000$ lung metastases; significant differences compared to ASML ${ }^{\text {wt }}$-bearing rats: *, and between ASML-CD151/Tspan ${ }^{\mathrm{kd}}$ versus $-\mathrm{CD} 151^{\mathrm{kd}}$ or Tpsan $8^{\mathrm{kd}}$ bearing rats: s; (F) recovery of CD151 and Tspan8 in lung and LN lysates of control and tumor-bearing rats. (G) Rats (3/group) received a single injected of dye-labeled exosomes, iv. Rats were sacrificed after 48h; $(\mathrm{H})$ rats (3/group) received three injected of dye-labeled exosomes in $3 \mathrm{~d}$ intervals, ifp, and were sacrificed $48 \mathrm{~h}$ after the last injection; $(\mathrm{G}, \mathrm{H})$ lymphatic organs were excised and the recovery of dye-labeled cells (exosome uptake) was evaluated by flow cytometry. The mean $\pm \mathrm{SD}$ of dye-labeled cells is shown; significant differences to the uptake of ASML ${ }^{\text {wt }}$ exosomes: *; (I) Rats (5/group) received 1x10 $0^{6}$ ASML-CD151/Tspan8 $8^{\mathrm{kd}}$ cells ifp and starting at day -6 in $3 \mathrm{~d}$ intervals, $100 \mu \mathrm{g}$ exosomes, ifp. Rats were scarified after $21 \mathrm{~d}$. Recovery of tumor cells in draining LN, lung and BM was evaluated by flow cytometry after staining for the ASML marker C4.4A; the mean $\mathrm{No} \pm \mathrm{SD}$ of tumor cells / $10^{3}$ cells is shown; significant differences to ASML-CD151/ Tspan $8^{\mathrm{kd}}$ bearing rats: *. A CD151 $1^{\mathrm{kd}}$ or a Tspan $8^{\mathrm{kd}}$ retards tumor growth. ASML-CD151/Tspan $8^{\mathrm{kd}}$ cells rarely metastasize. ASML-CD151 ${ }^{\mathrm{kd}}$ and/or ASML-Tspan $8^{\mathrm{kd}}$ exosomes are poorly recovered in lymphoid organs, which is accompanied by ASML-Tspan $8^{\mathrm{kd}}$ exosome retention at the injection site. 
exosomes is reduced in bone marrow (BM), peritoneal exudate (PEC) and lung. Instead more exosomes are retained in the blood (Fig.1G), which could indicate a requirement for Tspan 8 to leave the blood stream. After repeated ifp application, recovery in lymphoid organs, lung and liver was reduced in rats receiving ASML-CD151 kd and/or -Tspan $8^{\mathrm{kd}}$ exosomes. Recovery of ASML-Tspan $8^{\mathrm{kd}}$ and $-\mathrm{CD} 151 /$ Tspan $8^{\mathrm{kd}}$ exosomes being particularly poor in the blood (Fig.1H), confirms the Tspan8 engagement in crossing the blood barrier. Counterstaining with leukocyte markers revealed, as described [52], that all leukocyte subpopulations, but most pronounced $\mathrm{M} \varphi$ and DC take up exosomes. The uptake of ASML-CD $151^{\mathrm{kd}}$ and $-\mathrm{Tspan} 8^{\mathrm{kd}}$ exosomes is slightly and that of -CD $151 /$ Tspan $8^{\mathrm{kd}}$ exosomes is more severely impaired, which accounts for all leukocyte subpopulations. Notably, all leukocytes that uptake ASML exosomes are CD53 ${ }^{+}$, which suggests a particular engagement of CD53 in exosome uptake by hematopoietic cells of the rat (Supp.Fig.3).

To obtain a hint, whether exosomal CD151 and Tspan8 affect premetastatic organ preparation, rats receiving poorly metastatic ASML-CD151/Tspan $8^{\text {kd }}$ cells intrafoodpad (ifp) were pretreated with ASML ${ }^{\mathrm{wt}},-\mathrm{CD} 151^{\mathrm{kd}}$ or - Tspan $8^{\mathrm{kd}}$ exosomes. Exosome application $(200 \mu \mathrm{g} / \mathrm{rat}$, ifp) was repeated every 3 rd day. Rats were sacrificed 14 days after tumor cell application. The presence of ASMLCD151/Tspan $8^{\mathrm{kd}}$ cells was evaluated by flow cytometry in draining LNs, lung and BM. Except in rats receiving $\mathrm{ASML}^{\mathrm{wt}}$ exosomes, tumor cells were hardly recovered particularly in lung and BM, indicating that both exosomal Tspan8 and CD151 contribute to niche preparation (Fig.1I)

Nonetheless, CD151- and Tspan8-competent exosomes most efficiently restored metastatic settlement of poorly metastatic ASML-CD151/Tspan8 ${ }^{\mathrm{kd}}$ cells. Thus, we asked for the contribution of exosomal tetraspanins.

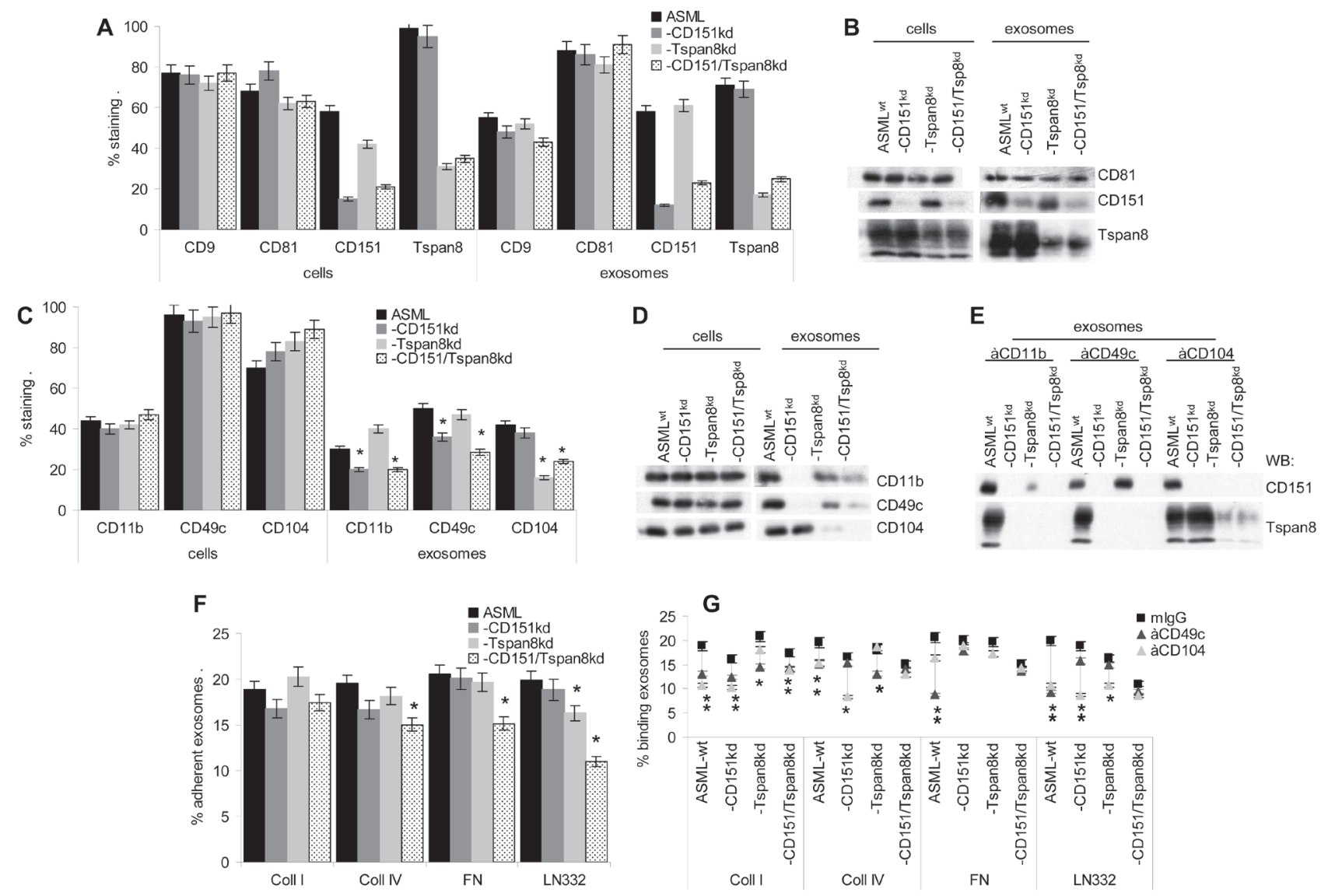

Figure 2: The impact of CD151 and Tspan8 on tetraspanin and adhesion molecule expression in ASML cells and exosomes. (A-D) ASML cells and exosomes were stained for expression of the indicated tetraspanins and adhesion molecules; (A,C) Mean \pm SD (3 assays) of the \% stained cells and exosomes; significant differences to ASML ${ }^{\text {wt }}$ cells and exosomes: * and (B,D) WB. (E) Exosome lysates of ASML ${ }^{\mathrm{wt}}$ and $-\mathrm{CD} 151^{\mathrm{kd}}$ and/or Tspan $8^{\mathrm{kd}}$ were precipitated with the indicated anti-integrin antibodies and were blotted with anti-CD151 and anti-Tspan8. (F,G) Dye-labeled exosomes were seeded on matrix-coated plates. Where indicated exosomes were preincubated with antibodies. After $2 \mathrm{~h}$ incubation, plates were washed and remaining fluorescence was evaluated in an ELISA reader. The mean percent \pm SD (triplicates) of bound exosomes is shown, (F) differences to ASML ${ }^{\text {wt }}$ exosomes: *; (G) differences by antibody preincubation: *. Expression of additional tetraspanins and of integrins is not affected in ASML-CD151 ${ }^{\mathrm{kd}}$ and/or -Tspan $8^{\mathrm{kd}}$ cells. Instead, integrin expression in exosomes is reduced corresponding to the associating tetraspanin. Exosomal CD151 and Tspan8 slightly affect exosome adhesion to matrix proteins. 


\section{Exosomal CD151 and Tspan8 account for matrix remodelling}

ASML cells express the tetraspanins CD151, Tspan8, CD9 and CD81. These tetraspanins are recovered in exosomes and the deficit of exosomal CD151 and/or Tspan8 has no significant impact on expression of the remaining tetraspanins in cells and exosomes (Fig.2A,2B). The major integrins in ASML are CD49c/(CD29), CD49f/ CD104 that is recognized by the B5.5 antibody and, though less pronounced $\mathrm{CD} 11 \mathrm{~b}$. Integrin expression is not affected in ASML-CD151 ${ }^{\mathrm{kd}}$, -Tspan $8^{\mathrm{kd}}$ and -CD151/Tspan $8^{\mathrm{kd}}$ cells, but $\mathrm{CD} 11 \mathrm{~b}$ and $\mathrm{CD} 49 \mathrm{c}$ expression is reduced in ASMLCD151 ${ }^{\mathrm{kd}}$ and $-\mathrm{CD} 151 / \mathrm{Tspan} 8^{\mathrm{kd}}$ exosomes and CD104 expression is reduced in ASML-Tspan $8^{\mathrm{kd}}$ and -CD151/ Tspan ${ }^{k d}$ exosomes (Fig.2C,2D). Reduced CD11b and CD49c expression in CD151 ${ }^{\mathrm{kd}}$ exosomes correlates with the preferential association of CD151 with CD11b and CD49c; strongly reduced recovery of CD104 in ASMLTspan $8^{\mathrm{kd}}$ and $-\mathrm{CD} 151 / \mathrm{Tspan} 8^{\mathrm{kd}}$ exosomes correlates with co-immunoprecipitation of CD104 with Tspan8 (Fig.2E), also described for ASML cells $[53,54]$.

Despite reduced integrin expression, adhesion of exosomes to matrix proteins was not severely affected by a CD151 or Tspan8 deficit, but adhesion of ASMLCD151/Tspan $8^{\mathrm{kd}}$ exosomes was mitigated (Fig.2F). Blocking exosome adhesion by anti-CD49c or anti-CD104 confirmed a pronounced contribution of CD151 to CD49cpromoted adhesion and of Tspan8 to CD104-supported

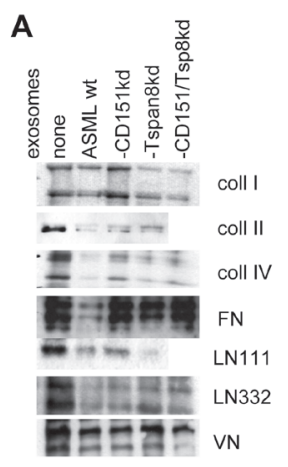

$\mathbf{F}$

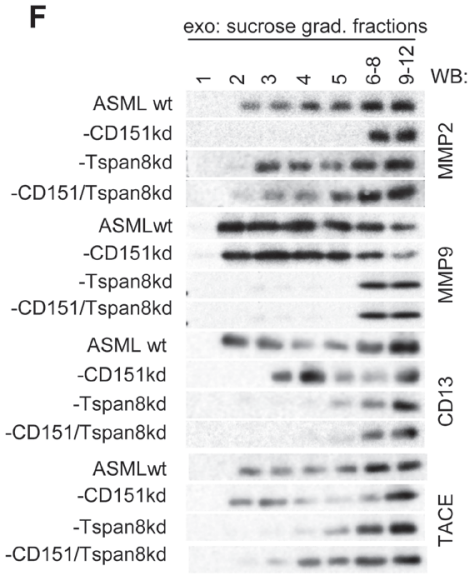

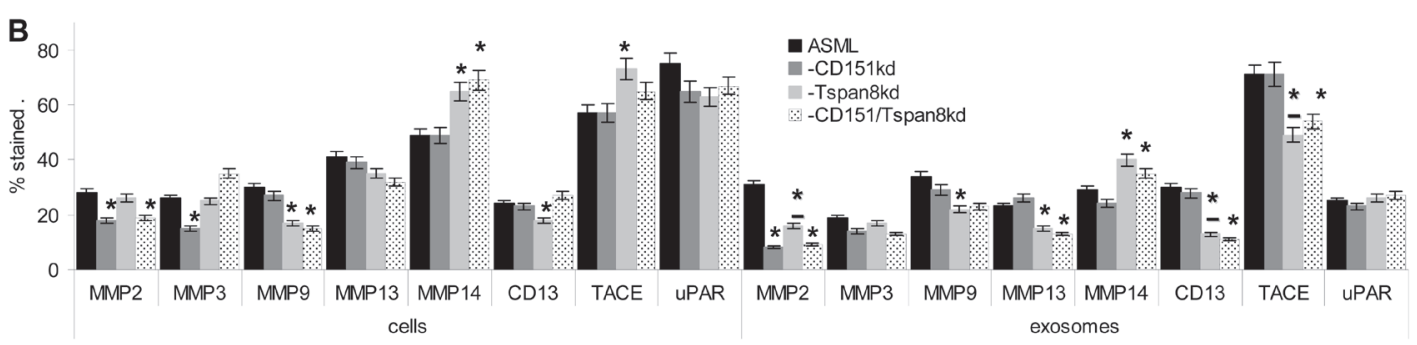

C

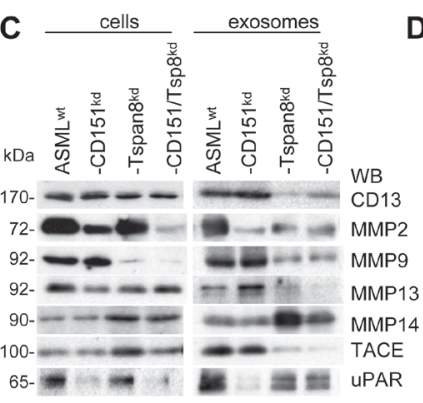

G

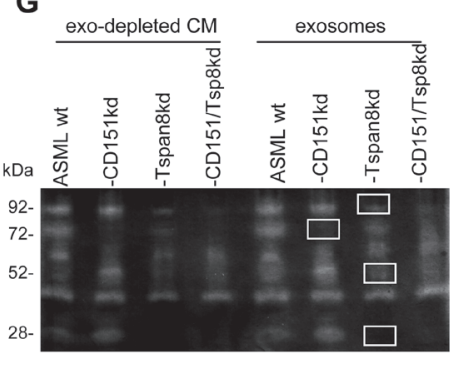

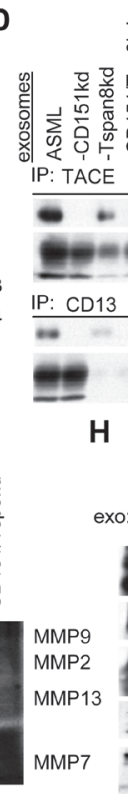
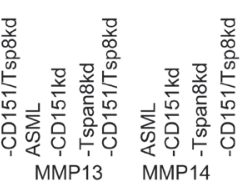

E



Figure 3: The association of exosomal CD151 and Tspan8 with proteases and the impact on matrix degradation and host cell invasiveness. (A) Matrix protein degradation (WB) by ASML ${ }^{\mathrm{wt}},-\mathrm{CD} 151^{\mathrm{kd}}$ and $/$ or Tspan $8^{\mathrm{kd}}$ exosomes; (B) Protease recovery in ASML ${ }^{\mathrm{wt}},-\mathrm{CD} 151^{\mathrm{kd}}$ and/or Tspan $8^{\mathrm{kd}}$ cells and exosomes; mean $\pm \mathrm{SD}$ (3 assays) of the percent stained cells and exosome-coated beads; significant differences to ASML ${ }^{\mathrm{wt}}$ cells/exosomes: *; significant differences between cells and exosomes: *; (C) protease recovery in ASML ${ }^{\mathrm{wt}}$ and $-\mathrm{CD} 151^{\mathrm{kd}}$ and/or -Tspan ${ }^{\mathrm{kd}}$ cells and exosomes as revealed by WB; (D) Coimmunoprecipitation of exosomal CD151 and Tspan8 with proteases and (E) of MMP2 and MMP9 with CD151 and Tspan8; (F) recovery of proteases in light and heavy sucrose density fractions in ASML ${ }^{\mathrm{wt}}$, $-\mathrm{CD} 151^{\mathrm{kd}}$ and/or -Tspan $8^{\mathrm{kd}}$ exosomes; (G) gelatin (zymography) degradation by ASML ${ }^{\mathrm{wt}},-\mathrm{CD} 151^{\mathrm{kd}}$ and/or Tspan $8^{\mathrm{kd}}$ exosomes and exosome-depleted conditioned medium; (H) native LnStr and LuFb matrix degradation (WB) by ASML ${ }^{\mathrm{wt}}$, $-\mathrm{CD} 151^{\mathrm{kd}}$ and/or Tspan $8^{\mathrm{kd}}$ exosomes and (I) inhibition of exosome-mediated matrix protein degradation by TACE, MMP2 and MMP9/MMP13 inhibitors (WB). Recovery of proteases in exosomes is mostly dictated by the association with CD151 and/or Tspan8 such that in the absence of CD151 mostly MMP2 and in the absence of Tspan8 mostly MMP9 expression / activity are strongly reduced. Exosomal TACE activity apparently depends on both Tspan8 and CD151. Reduced exosomal protease recovery has consequences on matrix protein, matrigel and native matrix degradation. 
adhesion. Though differences did not reach statistical significance in all instances, the failure to block ASMLCD151/Tspan $8^{\mathrm{kd}}$ exosome adhesion by either anti-CD49c or anti-CD104 confirms the importance of the tetraspaninassociated integrins in exosome targeting (Fig.2G).

Exosome binding to matrix proteins is accompanied by matrix degradation, which is affected in ASMLCD $151^{\mathrm{kd}}$, -Tspan $8^{\mathrm{kd}}$ and -CD151/Tspan $8^{\mathrm{kd}}$ exosomes. ASML-CD $151^{\mathrm{kd}}$ exosomes did not degrade coll I and FN and poorly degraded coll II and coll IV. Coll II, FN and more pronounced LN332 degradation was reduced in the presence of ASML-Tspan $8^{\mathrm{kd}}$ compared to ASML ${ }^{\mathrm{wt}}$ exosomes (Fig.3A). Reduced matrix degradation corresponds to reduced protease expression in exosomes. A CD151 ${ }^{\mathrm{kd}}$ mostly affects expression of MMP2 and MMP3, a Tspan8 ${ }^{\mathrm{kd}}$ affects MMP9, but promotes MMP14 and TACE expression. Furthermore, while exosomal MMP9 and MMP14 expression corresponds to cellular expression, MMP2, CD13 and TACE expression is reduced in ASMLTspan $8^{\mathrm{kd}}$ exosomes (Fig.3B,3C). Notably, recovery in exosomes correlates with the tetraspanin association. Thus, after mild exosome lysis, CD13 (mostly), MMP9 and TACE co-immunoprecipitate with Tspan8, but not CD151. MMP2 and MMP14 co-immunoprecipitate with CD151, but not Tspan8 and exosomal MMP13 does not co-immunoprecipitate with CD151 or Tspan8, which was confirmed in the reverse setting in cell and exosome lysates for MMP2 and MMP9 (Fig.3D,3E). Furthermore, MMP2 was not recovered in light sucrose gradient fractions of ASML-CD151 ${ }^{\mathrm{kd}}$ exosomes, and MMP9, CD13 and TACE were not or poorly recovered in light sucrose gradient fractions of ASML-Tspan $8^{\mathrm{kd}}$ exosomes (Fig.3F). Thus, changes in the exosomal versus the cellular protease profile are due to the selective association of CD151 with MMP2 and MMP14 and of Tspan8 with CD13, MMP9 and TACE. Zymography confirmed the absence of active MMP2 in CD151 ${ }^{\mathrm{kd}}$ exosomes, strongly reduced MMP9 activity in ASML-Tspan $8^{\mathrm{kd}}$ exosomes and poor recovery of active MMP2 and MMP9 in CD151/Tspan $8^{\mathrm{kd}}$ exosomes (Fig.3G). The impact of CD151- and/or Tspan8-associated exosomal proteases also was apparent in degradation of the natural matrix of LnStr and LuFb. ASML-CD $151^{\mathrm{kd}}$ exosomes did not degrade coll I and LN111 and ASMLTspan ${ }^{\mathrm{kd}}$ exosomes did not degrade LN332 (Fig.3H). Confirming the contribution of Tspan8-associated MMP9 and MMP13 to coll II, FN and LN332 modulation, degradation was abolished in the presence of an MMP9/ MMP13 inhibitor, while degradation of coll I, coll IV and FN, which require CD151-associated MMP2, was not seen in the presence of an MMP2 inhibitor. LN332, coll IV and FN degradation was also impaired in the presence of the TACE inhibitor TAPI (Fig.3I).

Exosomal tetraspanin-integrin and tetraspaninprotease complexes also modulate the host matrix. Thus, lymph node stroma (LnStr), lung fibroblasts $(\mathrm{LuFb})$ and rat endothelial cells (RAEC) adhere more strongly to their own matrix, when modulated by ASML wt exosomes. Pronounced adhesion is not seen after pretreatment with ASML-CD151 $1^{\mathrm{kd}}$ or -CD151/Tspan $8^{\mathrm{kd}}$ exosomes (Fig.4A). Adhesion of stroma cells to the ASML wt exosomemodulated matrix is accompanied by actin reorganization [51], which is also seen, though weaker after treatment with ASML-CD151 kd exosomes (Fig.4B). Furthermore, $\mathrm{ASML}^{\mathrm{wt}}$ and $-\mathrm{CD} 151^{\mathrm{kd}}$ exosome-treated host matrices slightly promoted host cells motility, even though the effect was far weaker than on tumor cell motility (see Suppl. Fig.2B). Matrices treated with exosomes from Tspan $8^{\mathrm{kd}}$ or CD151/Tspan $8^{\mathrm{kd}}$ exosomes did not significantly affect host cell motility (Fig.4C). Finally, the deficit of protease activity in $\mathrm{CD} 151^{\mathrm{kd}}$ and/or Tspan $8^{\mathrm{kd}}$ exosomes had severe consequences on host cell invasiveness such that LnStr and RAEC poorly invaded matrigel, invasiveness being about 5-fold reduced in matrigel pretreated with ASML-CD151/Tspan $8^{\mathrm{kd}}$ exosomes compared to ASML ${ }^{\text {wt }}$ exosomes (Fig.4D).

Taken together, exosomal CD151 and Tspan8 account for integrin and protease recruitment [46-51], which results in matrix modulation [55]. Our findings fit with ASML ${ }^{\text {wt }}$ exosomes restoring metastatic capacity of ASML-CD151/Tspan $8^{\mathrm{kd}}$ cells as well as the inefficacy of ASML-CD151/Tspan8 ${ }^{\mathrm{kd}}$ exosomes to do so.

Besides modulating the extracellular matrix, tumor exosomes contribute to reprogramming host cells in premetastatic organs $[11,56,57]$ and can affect the hematopoietic system [10,52,58-61]. Finally, tumor exosomes can affect neighboring tumor cells [62]. As exosomal tetraspanin complexes are essential for exosome binding and uptake [32], exosomes from ASML-CD151 ${ }^{\mathrm{kd}}$ and/or -Tspan $8^{\mathrm{kd}}$ cells now allowed us to ask for a genuine contribution of CD151 and Tspan8.

\section{Exosomal CD151 and Tspan8 and host cell modulation}

Based on previous work demonstrating a major contribution of ASML exosomes to stroma cell protease and adhesion molecule as well as chemokine and chemokine receptor expression [63], we asked for a selective contribution of exosomal CD151 and Tspan8 in LnStr, LuFb and RAEC as well as LNC and BMC modulation. Exosomes were cocultured with $\mathrm{LnStr}, \mathrm{LuFb}$, RAEC and freshly harvested BMC and LNC for $48 \mathrm{~h}$.

We first controlled the impact of exosomal CD151 and Tspan 8 on protease expression. Only ASML wt exosome uptake by $\mathrm{LuFb}$ and more pronounced by LnStr promoted TACE, MMP14, TIMP1 and TIMP2 expression. ADAMTS1, ADAMTS5 and UPA upregulation appeared largely CD151-dependent. Expression of MMP2 and MMP9 was not affected by short term in vitro coculture (Fig.5A,5B). However, distinct to the short term in vitro coculture, repeated ASML exosome application promoted 
TACE, but also MMP2 and MMP9 upregulation that was strongest in ASML ${ }^{\text {wt }}$ exosome-treated rats. ASML-CD151/ Tspan $8^{\mathrm{kd}}$ exosomes did not induce MMP9 and TACE upregulation; MMP2 expression was hardly increased in ASML-CD $151^{\mathrm{kd}}$ exosome- and MMP9 and TACE expression in -Tspan $8^{\mathrm{kd}}$ exosome-treated rats (Fig.5C). These findings fitted to the appearance of LN metastases with poor recovery of MMP2 in ASML-CD151 ${ }^{\mathrm{kd}}$ tumors, poor recovery of MMP9 in both ASML-CD151 kd and ASML-Tspan $8^{\mathrm{kd}}$ tumors and very few ADAM $17^{+}$cells in ASML-Tspan $8^{\mathrm{kd}}$ tumors. The reduced protease recovery was accompanied by a dense coll IV and LN332 matrix in ASML-CD151/Tspan8 ${ }^{\mathrm{kd}}$ tumors (Suppl.Fig.4). Immunohistology of LN sections from ASML ${ }^{\text {wt }}$ exosometreated rats additionally showed upregulated expression of CD49c and CD49d that was not seen in ASML-CD151/ Tspan $8^{\mathrm{kd}}$ exosome-treated rats. Upregulation of $\alpha 6 \beta 4$ was only seen in ASML ${ }^{\mathrm{wt}}$ and ASML-CD151 ${ }^{\mathrm{kd}}$ exosometreated rats (Fig.5D).

Thus, ASML exosomes exert a strong impact on host cell protease expression that partly depended on exosomal CD151 or Tspan8.

Premetastatic niches are frequently characterized by changes in chemokines and their receptors [64], where we controlled for a selective impact of exosomal CD151 and Tspan8 in LnStr, RAEC and LuFb after $48 \mathrm{~h}$ coculture with ASML ${ }^{\text {wt }}$, $-\mathrm{CD} 151^{\mathrm{kd}}$ and/or -Tspan $8^{\mathrm{kd}}$ exosomes. LnStr, $\mathrm{LuFb}$ and RAEC did not uniformly respond to ASML exosome treatment. Only SDF1 and VEGFR1 were upregulated in all three cell populations after treatment with ASML ${ }^{\text {wt }}$ exosomes. However, SDF1 depended more on CD151 than Tspan8, whereas VEGFR1 stimulation required CD151 and Tspan8. CXCR4 and VEGFR3 expression, stimulated in $\mathrm{LnStr}$ and $\mathrm{LuFb}$, respectively in

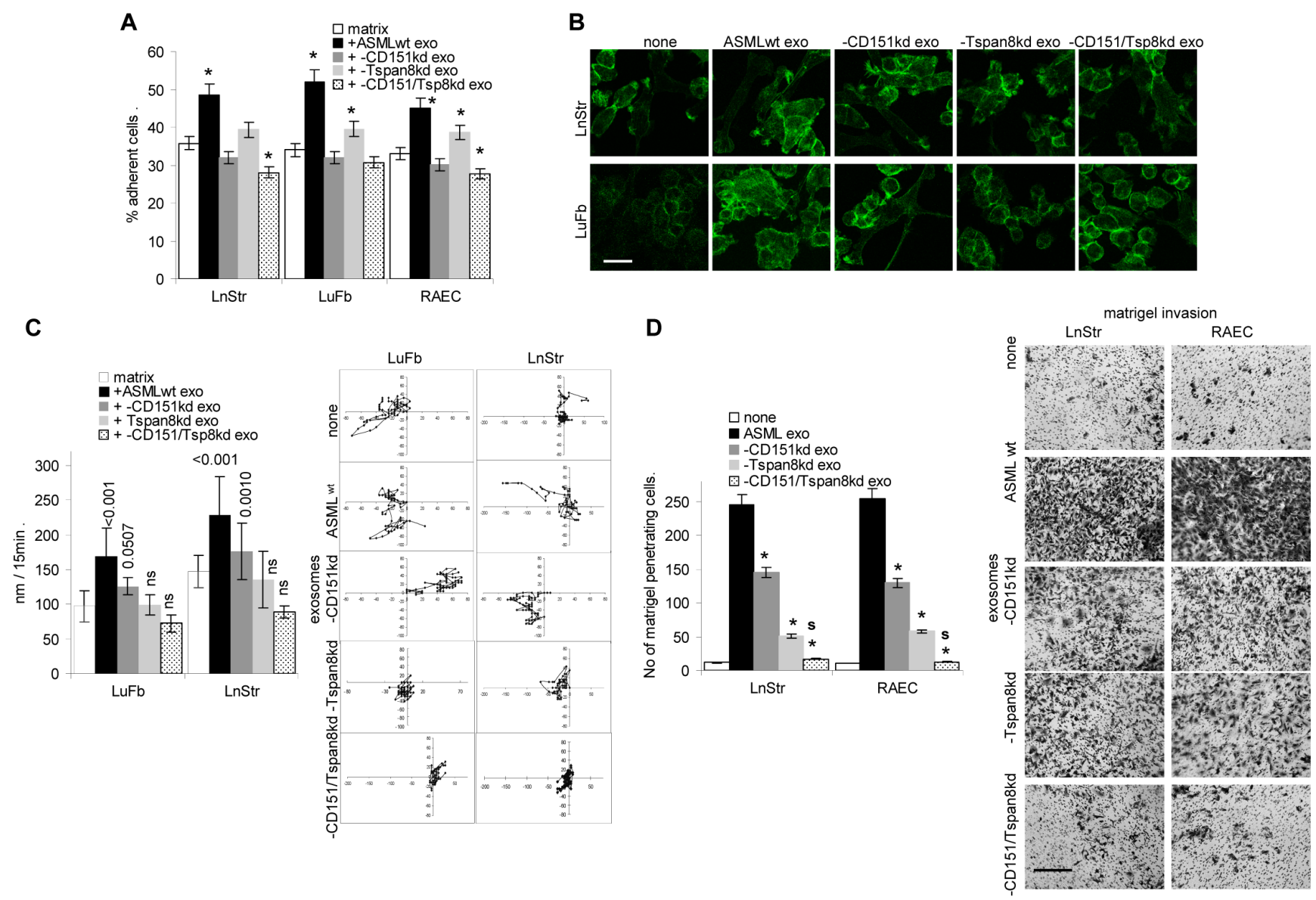

Figure 4: The impact of exosomal CD151 and Tspan8 on host cell adhesion, motility and invasiveness. (A) LnStr, LuFb and RAEC were seeded on their corresponding untreated or exosome-treated matrix; mean $\pm \mathrm{SD}$ of adherent cells; significant differences compared to the native matrix: *; (B) confocal microscopy of actin cytoskeleton organization in LnStr and LuFb depending on exosome treated stroma (scale bar: $10 \mu \mathrm{m}$ ); (C) videomicroscopy of LuFb and LnStr that were seeded on their untreated or ASML exosome-treated matrix. The relative migration of cells during $12 \mathrm{~h}$ incubation (mean of 20 individual cells) and a representative example are shown; significant differences in migration due to ASML exosome treatment are indicated; (D) Matrigel penetration and invasion of LnStr and RAEC in dependence on CD151- and/or Tspan8-competent exosomes; the mean \pm SD (triplicates) of penetrating cells; significant differences to untreated matrigel: *; significant difference between ASML-CD151/Tspan $8^{\mathrm{kd}}$ versus -CD151 ${ }^{\mathrm{kd}}$ or -Tspan $8^{\mathrm{kd}}$ exosomes: s; and representative examples of invasion (scale bar: $250 \mu \mathrm{m}$ ). Exosomal CD151 and Tspan8 slightly affect host cell adhesion to matrix proteins, but support stroma cell motility and invasiveness, which might be promoted by exosomal proteases. 

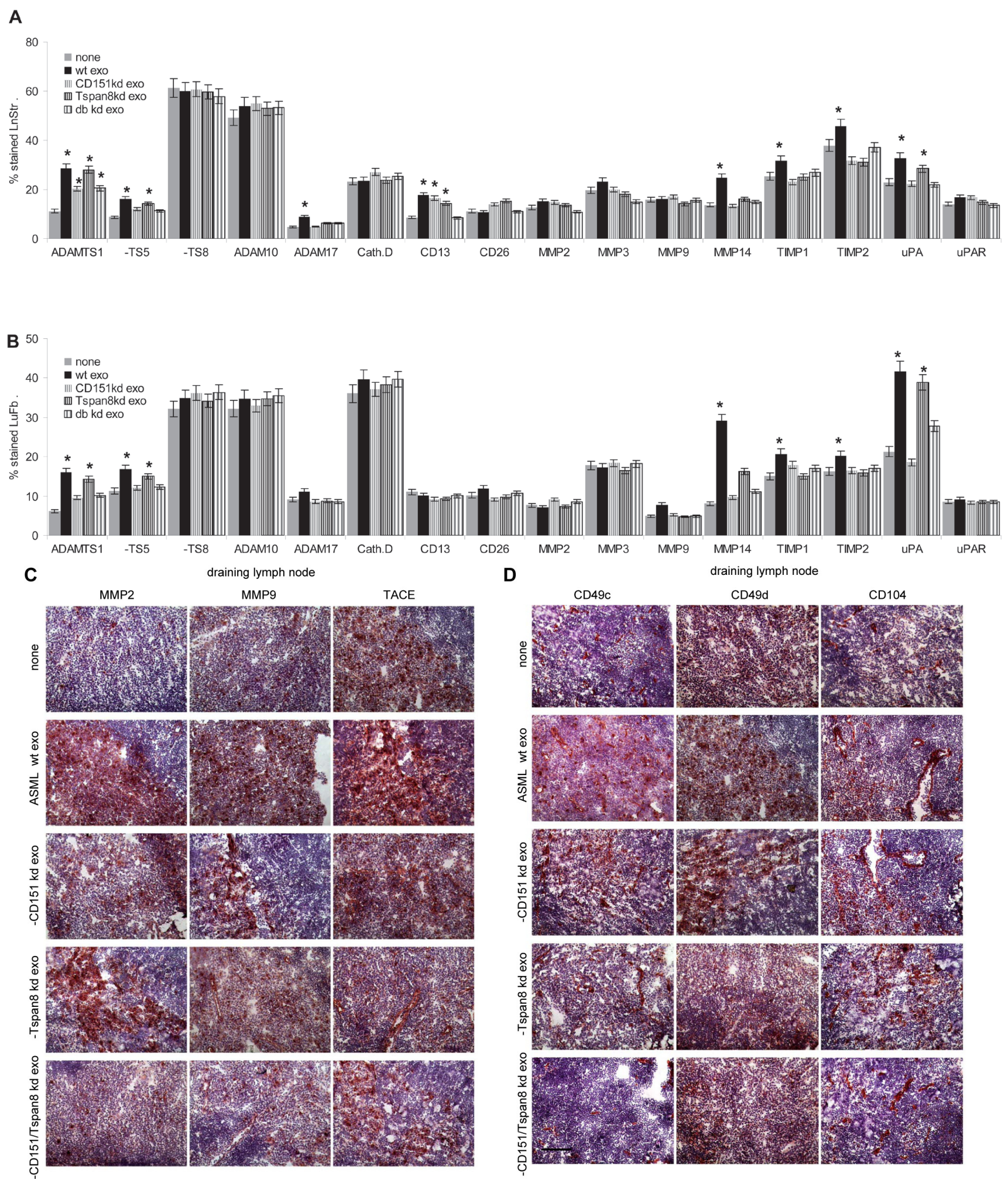

Figure 5: The impact of exosomal CD151 and Tspan8 on host cell adhesion molecule and protease expression. (A,B) Flow cytometry analysis of protease expression in LnStr and LuFb after coculture with ASML ${ }^{\mathrm{wt}},-\mathrm{CD} 151^{\mathrm{kd}}$ and/or -Tspan $8^{\mathrm{kd}}$ exosomes; mean percent $\pm \mathrm{SD}$ ( 3 assays) of stained cells; significant differences to untreated cells: *; (C,D) immunohistology of protease and adhesion molecule expression in draining LN after repeated ifp application of ASML ${ }^{\mathrm{wt}}$ or $-\mathrm{CD} 151^{\mathrm{kd}}$ and/or $-\mathrm{Tspan} 8^{\mathrm{kd}}$ exosomes (scale bar: $150 \mu \mathrm{m}$ ). Short term in vitro coculture of stroma cells with ASML exosomes hardly affected protease and adhesion molecule (data not shown) expression. Instead, after repeated exosome application in vivo, ASML ${ }^{\text {wt }}$ exosomes particularly promoted MMP2, MMP9 and TACE as well as CD49c, CD49d and CD104 expression. CD104 and TACE upregulation were weakened in ASML-CD151/Tspan8 ${ }^{\mathrm{kd}}$ exosome treated rats and CD49c, CD49d, MMP2 and MMP9 expression were not supported. 
LnStr and RAEC, required Tspan8-competent exosomes. FGFR upregulation in $\mathrm{LnStr}$ and $\mathrm{LuFb}$ was independent of exosomal CD151 and Tspan8 (Fig.6A-6D). These findings could be confirmed by staining LN of ASML exosometreated rats (Fig.6E).

Taken together, a strong induction of cytokine/ chemokine and -receptor expression, most notably of VEGFR3 in RAEC as well as of CXCR4 both depend on Tspan8.

Tumor exosomes were reported to promote inflammation and immunosuppression [59-61,65]. Indeed, inflammatory TNF $\alpha$ and IL6 expression became upregulated in $\mathrm{BMC}$ and $\mathrm{LNC}$. The latter also expressing C3 and HSP70 at an increased level. We also noted upregulated expression of the immunosuppressive cytokine IL10, but expression of the effector cytokines IL2 and IFN $\gamma$ as well as of the activation markers CD44v6 and CD69 were unaltered or slightly reduced only in $\mathrm{ASM}^{\mathrm{wt}}$ exosome treated LNC. Upregulation of TGF $\beta$ was more pronounced in BMC than LNC cocultures, where it should be noted that ASML exosomes more strongly affected BMC than LNC. Confirming the exosome-induced shift towards inflammation / immunosuppression, TLR4, p-Stat3 and p-Stat4 expression were upregulated in BMC and LNC (data not shown) and FoxP3 expression was increased in LNC, but NFAT expression was not altered. Furthermore, while ASML-CD151/Tspan $8^{\mathrm{kd}}$ exosomes hardly exerted any effect, in most instances ASML ${ }^{\text {wt }}$ exosomes had the strongest impact (Fig.7A-7F).

In brief, there was a shift towards inflammatory and immunosuppressive cytokines without evidence for significantly impaired effector cytokines. The stronger impact on BMC than LNC and the missing effect of ASML-CD151/Tspan8 ${ }^{\mathrm{kd}}$ exosomes are in line with the more ready uptake of ASML exosomes by BMC and the poor uptake of ASML-CD151/Tspan $8^{\text {kd }}$ exosomes (Suppl.Fig.3). Furthermore, though changes were most pronounced after coculture with ASML ${ }^{\text {wt }}$ exosomes, they were not abolished after coculture with $-\mathrm{CD} 151^{\mathrm{kd}}$ or $-T s p a n 8^{\mathrm{kd}}$ exosomes, indicating that the major contribution of exosomal tetraspanins may rely on binding rather than distinct message transfer.

\section{Exosomal CD151 and Tspan8 and the feedback towards non-metastasizing tumor cells}

As exosomes itinerate [66], tumor exosomes could well affect neighboring tumor cells, such that tumor stem cell exosomes modulate non-CIC.

The CD $151^{\mathrm{kd}}$ and/or Tspan $8^{\mathrm{kd}}$ had no major impact on receptor tyrosine kinase (RTK) expression with the exception of VEGFR1, which is weakly expressed in $\mathrm{ASML}^{\mathrm{wt}}$ cells, expression being further reduced in ASMLCD151 ${ }^{\mathrm{kd}}$ and ASML-Tspan $8^{\mathrm{kd}}$ cells (Suppl.Fig.5A). When ASML-CD151/Tspan ${ }^{\mathrm{kd}}$ cells were cocultured with ASML ${ }^{\text {wt }}$ exosomes, VEGFR1 and, predominantly, VEGFR3 expression became upregulated (Suppl.Fig.5C5E). As expression in exosomes was low (Suppl.Fig.5B), a direct protein transfer can be excluded [63].

In concern of EMT-related factors including EMTassociated transcription factors, only FN, vimentin, Notch and, borderline, Snail were downregulated in ASML$\mathrm{CD} 151^{\mathrm{kd}}$ and/or ASML-Tspan ${ }^{\mathrm{kd}}$ cells. In exosomes, only expression of Slug and, slightly of Notch was reduced by the $\mathrm{CD} 151^{\mathrm{kd}}$ and/or the Tspan $8^{\mathrm{kd}}$ (Fig.8A,8B). Instead, after coculture of ASML-CD151/Tspan $8^{\mathrm{kd}}$ cells with exosomes, expression of vimentin, Slug, Twist and, most strikingly, Notch became upregulated. While vimentin, Snail and Slug appeared to depend mostly on Tspan8, the strong upregulation of Notch required CD151- and Tspan8-competent exosomes (Fig.8C-8E).

Coculture of poorly metastatic ASML-CD151/ Tspan8 ${ }^{\mathrm{kd}}$ cells with ASML $^{\text {wt }}$ exosomes promoting upregulation of several EMT-related proteins and transcription factors supports the hypothesis that exosomes from metastasizing tumor cells can drive neighboring nonmetastatic tumor cells into EMT.

In brief, the metastasis-supporting activity of the tetraspanins CD151 and Tspan8 most likely is promoted by exosomes, which strongly modulate the host matrix, affect hematopoietic and stroma cell activation including (lymph)angiogenesis. In addition, the transfer of exosomes into neighboring non-metastatic tumor cells supports expression of EMT-related genes.

\section{DISCUSSION}

Exosomes are important intercellular communicators $[14,15]$ and it was suggested that tumor exosomes, particularly cancer initiating cell exosomes account for premetastatic niche preparation [9-11]. Although the mechanisms are not yet elucidated, it is evident that exosomal targeting structures as well as transferred proteins and most prominently transferred miRNA account for the reprogramming of host cells towards supporting settlement and growth of disseminated tumor cells [9]. As tetraspanins are constitutive exosome components and known to be engaged in exosome binding and uptake [32], we speculated that the metastasis-promoting tetraspanins CD151 and Tspan8 $[25,26,37-40]$ could play a central role in the process of tumor exosome-mediated host modulation. We demonstrate that ASML-CD151/ Tspan ${ }^{k d}$ cells largely lost the capacity to metastasize, but regain metastatic capacity by the support of ASML ${ }^{\text {wt }}$ exosomes. Deciphering the role of exosomal CD151 and Tspan8 revealed that both tetraspanins contribute to matrix degradation that supports tumor and host cell motility, affect stroma and hematopoietic cells and are engaged in a feedback towards non-metastatic tumor cells, where they promote EMT. 

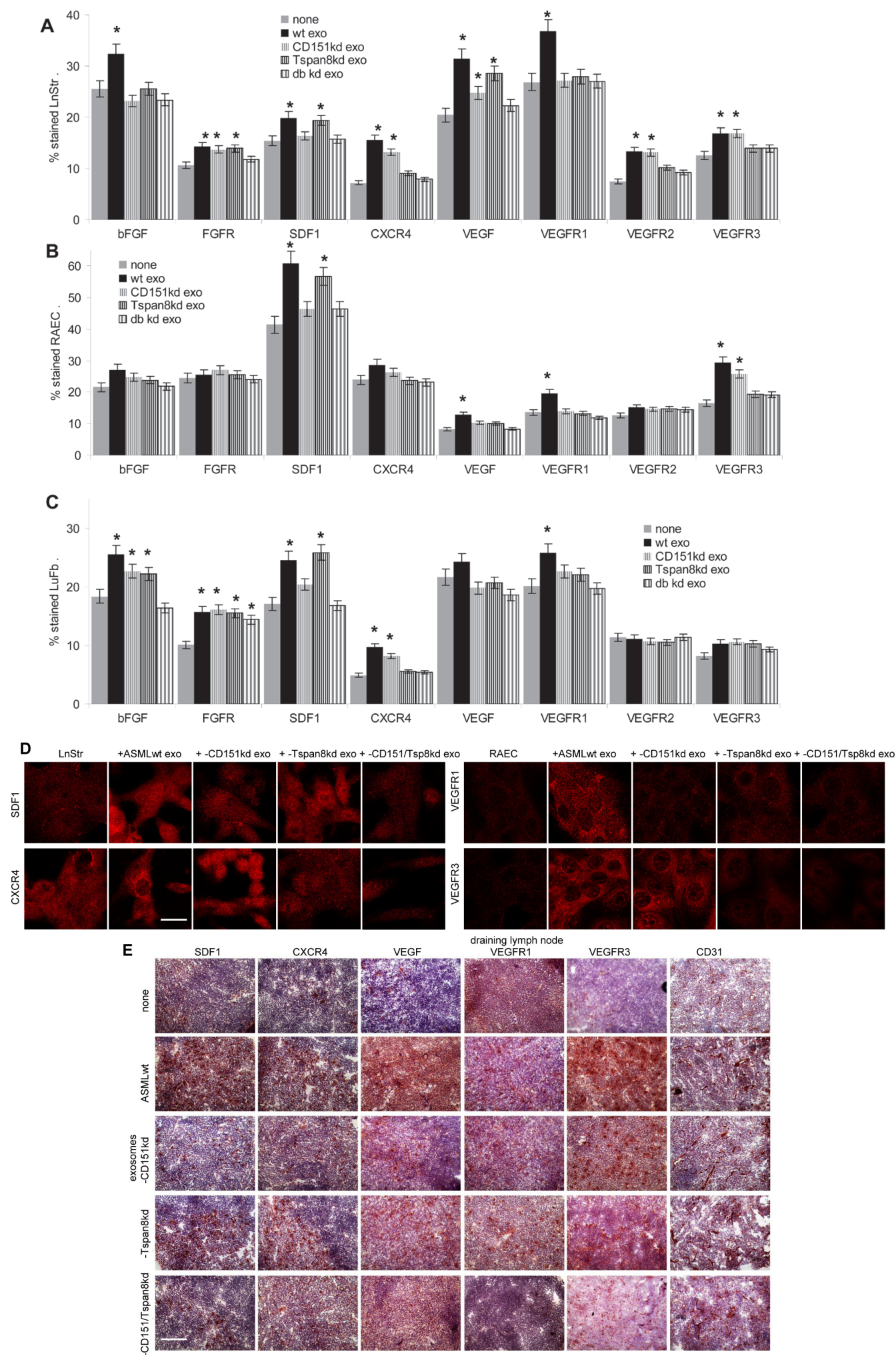

Figure 6: Stroma and endothelial cell responses to exosomal CD151 and Tspan8. (A-C) Flow cytometry analysis of LnStr, RAEC and LuFb after coculture with ASML ${ }^{\mathrm{wt}},-\mathrm{CD} 151^{\mathrm{kd}}$ and/or $-T s p a n 8^{\mathrm{kd}}$ exosomes; mean percent $\pm \mathrm{SD}$ ( 3 assays) of stained cells; significant differences to untreated cells: *; (D) representative examples of SDF1, CXCR4, VEGFR1 and VEGFR3 expression in LnStr and RAEC

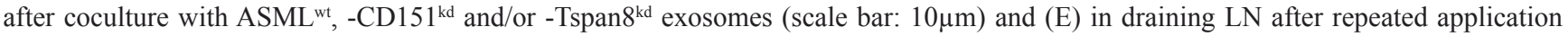
of ASML ${ }^{\mathrm{wt}},-\mathrm{CD} 151^{\mathrm{kd}}$ and/or $-\mathrm{Tspan} 8^{\mathrm{kd}}$ exosomes (scale bar: $150 \mu \mathrm{m}$ ). Exosomal CD151 and Tspan8 promote upregulated expression of several growth factors and their receptors, which varies depending on the target cell. Upregulated expression of some markers, e.g. bFGF and VEGFR1 essentially depends on the presence of both CD151 and Tspan8, whereas SDF1 and FGFR expression is independent of exosomal CD151 and Tspan8. However, exosomal Tspan8 is essential for VEGFR3 upregulation. 

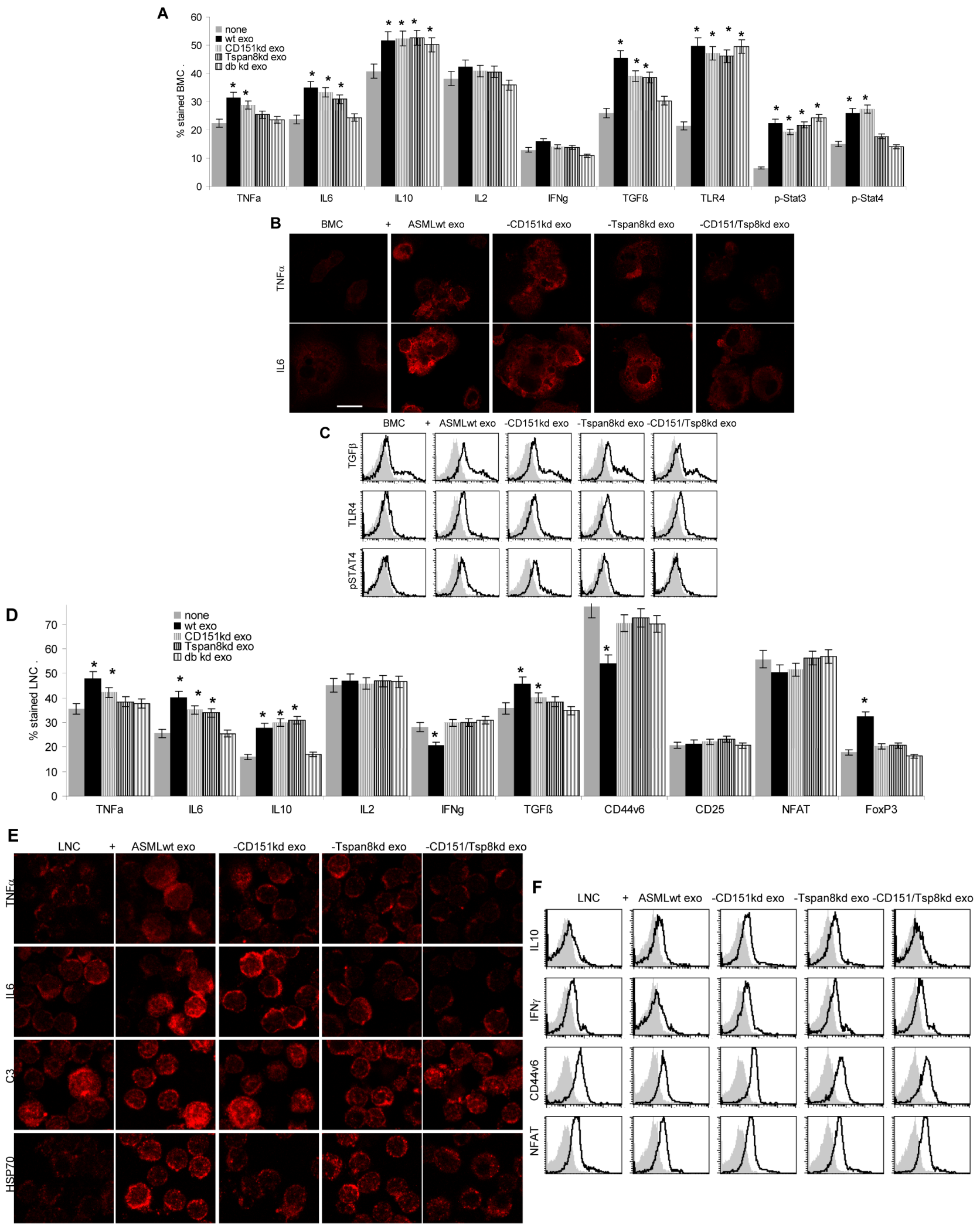

Figure 7: Leukocyte responses to exosomal CD151 and Tspan8. (A-F) BMC and LNC were cocultured with ASML ${ }^{\mathrm{wt}}$, -CD151 $1^{\mathrm{kd}}$ and/or -Tspan $8^{\mathrm{kd}}$ exosomes; (A,C,D,F) cytokine and activation marker expression as well as activation of the JAK/STAT signaling pathway and of NFAT and FoxP3 was evaluated by flow cytometry; mean percent \pm SD of stained cells; significant differences to BMC and LNC cultured in the absence of exosomes: * and representative examples; (B,E) representative examples of confocal microscopy (scale bar: $10 \mu \mathrm{m})$. In BMC and LNC, ASML exosomes strengthen inflammatory cytokine expression; These effects are supported by, but not exclusively depending on exosomal CD151 and Tspan8. 


\section{Loss of metastasis formation by a double knockdown of CD151 and Tspan8}

In advance of evaluating the impact of exosomal tetraspanins on the crosstalk with the host, we reassured that ASML-CD151/Tspan $8^{\mathrm{kd}}$ cells lost metastatic potential. The in vivo and in vitro growth characteristics of ASMLCD151/Tspan $8^{\mathrm{kd}}$ cells resembled the sum of that reported for ASML-CD151 $1^{\mathrm{kd}}$ and ASML-Tspan ${ }^{\mathrm{kd}}$ cells [51]. Similar to ASML-Tspan ${ }^{\mathrm{kd}}$ cells, anchorage independent growth of ASML-CD151/Tspan $8^{\mathrm{kd}}$ cells was strongly impaired and apoptosis resistance was more severely affected than in ASML-CD151 $1^{\mathrm{kd}}$ or ASML-Tspan ${ }^{\mathrm{kd}}$ cells (data not shown). Migration was similar to that of ASML ${ }^{\text {wt }}$ cells, i.e. the striking gain in motility seen in ASMLCD151 ${ }^{\mathrm{kd}}$ cells was annulated. ASML-CD151/Tspan8 $8^{\mathrm{kd}}$ cells were poorly invasive and scarce transendothelial cell migration resembled that of ASML-Tspan $8^{\mathrm{kd}}$ cells without a measurable contribution of CD151. These findings, which confirmed our results on ASML-CD $151^{\mathrm{kd}}$ and ASML-Tspan $8^{\mathrm{kd}}$ cells, provided a solid basis to answer the question on the role of exosomal CD151 and Tspan8 in metastasis.

\section{Exosomal CD151 and Tspan8 and the host matrix}

Exosomes maintain the tetraspanin webs of their cells of origin [24], the presented data confirming the general validity of TEM complex recovery in exosomes. Thus, the tetraspanin - integrin associations are maintained in exosomes. Reduced expression of either CD151 or Tspan8 apparently is not sufficient to significantly alter exosome-binding to matrix proteins. This includes the adhesion promoting, but migration inhibitory effect of CD151 that was visible, but less pronounced in exosomes than cells [51]. Instead, the exosomal tetraspanin-protease complexes displayed full activity with a strong impact on invasion, where matrix degradation became strongly

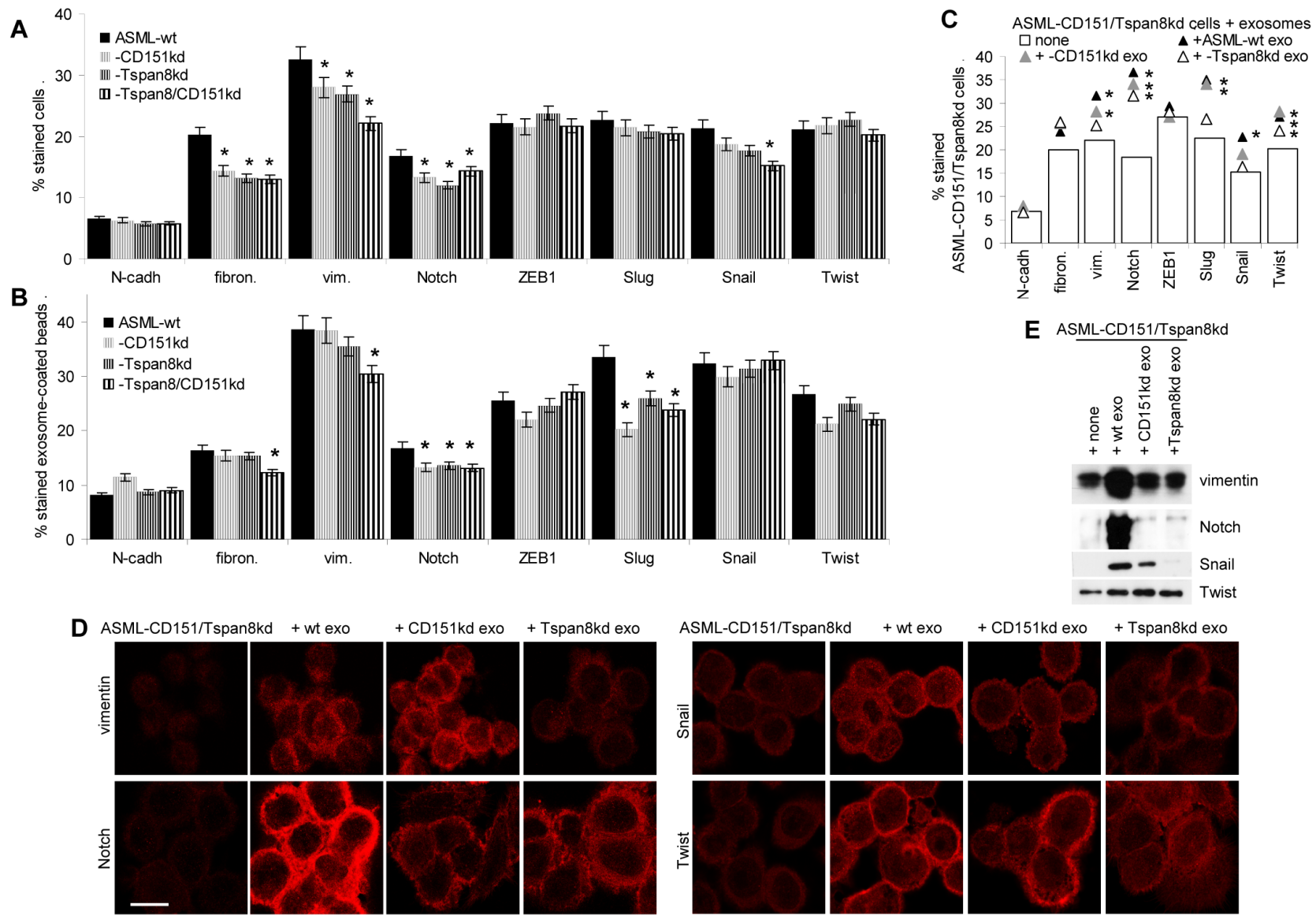

Figure 8: Metastasis-supporting exosomes and EMT: ASML-CD151/Tspan8 ${ }^{\mathrm{kd}}$ cells were cocultured for $48 \mathrm{~h}$ with ASML ${ }^{\mathrm{wt}},-$ CD151 $^{\mathrm{kd}}$ or - Tspan8 $8^{\mathrm{kd}}$ exosomes. (A,B) ASML ${ }^{\mathrm{wt}},-\mathrm{CD} 151^{\mathrm{kd}}$ and $/$ or $-\mathrm{Tspan} 8^{\mathrm{kd}}$ cells and exosomes stained for the indicated EMT markers; mean percent \pm SD of stained cells / exosome-coated latex beads; significant differences to ASML ${ }^{\text {wt }}$ cells / exosomes: *. (C-E) EMT gene expression evaluated by flow cytometry (mean percent stained cells, 3 assays); significant differences to ASML-CD151/ Tspan ${ }^{\mathrm{kd}}$ cells cultured in the absence of exosomes: ${ }^{*}$, confocal microscopy (scale bar: $10 \mu \mathrm{m}$ ) and WB. Expression of the EMT related vimentin protein as well as of the transcription factors Slug, Snail, Twist and, particularly, Notch, becomes upregulated, upregulation of vimentin and Snail predominantly depending on Tspan8 and of Notch on CD151 and Tspan8. 
impaired or abolished by a deficit of the tetraspanin partner for proteases. Thus, a deficit in CD151 was accompanied by a failure to degrade coll I or FN and degradation of coll IV was reduced, which correlated with poor recovery of CD151-linked MMP2 in ASML-CD151 ${ }^{\mathrm{kd}}$ cells. Due to the preferential association of MMP9 with Tspan8, ASMLTspan $8^{\mathrm{kd}}$ exosomes poorly degraded coll I, coll IV and LN332 and degradation was abolished in the presence of an MMP9 inhibitor. The TACE inhibitor TAPI impaired LN332 and partly coll II, coll IV and FN degradation, which could be due to the preferential, though not exclusive association with Tspan8. Importantly, exosomal tetraspanin-associated proteases modulate stroma matrices in vivo such that invasion is facilitated. This became most obvious for Tspan8 upon iv and ifp application of dyelabeled exosomes, where Tspan $8^{\mathrm{kd}}$ and CD151/Tspan $8^{\mathrm{kd}}$ exosomes were retained in the blood after iv and poorly recovered in the blood after ifp application, which fitted to the deficit of ASML-Tspan $8^{\mathrm{kd}}$ and -CD151/Tspan $8^{\mathrm{kd}}$ cells to pass an endothelial cell monolayer and previous reports on Tspan8 preferentially targeting endothelial cells $[32,67]$.

In brief, the crosstalk between tumor exosomes and the matrix is strongly influenced by exosomal tetraspanins. Due to their associations with integrins and proteases, the tetraspanin web facilitates binding, motility and matrix degradation.

\section{Stroma and hematopoietic cell modulation by exosomal CD151 and Tspan8}

Coculture of LnStr, LuFb, RAEC and freshly harvested $\mathrm{BMC}$ or $\mathrm{LNC}$ with $\mathrm{ASML}{ }^{\mathrm{wt}},-\mathrm{CD} 151^{\mathrm{kd}}$, -Tspan $8^{\mathrm{kd}}$ and -CD151/Tspan $8^{\mathrm{kd}}$ exosomes allowed appointing changes in target cells to be CD151- and/or Tspan8-dependent or -independent. However, it should be remembered that there is strong evidence that exosomes modulate target cells mostly via transferred miRNA [63]. As we have not yet explored the impact of CD151 and Tspan 8 on miRNA recruitment into exosomes, we presently cannot differentiate between exosomal CD151and Tspan8-mediated effects due to tetraspanin binding versus a potential impact due to transferred messages. Independent of this open question, exosomal CD151 and Tspan8 significantly contribute to target cell modulation, where we concentrated on adhesion molecules, proteases, chemokines and their receptors and, particularly in BMC and LNC on changes associated with immunosuppression and inflammation.

Exosome uptake significantly affected adhesion molecule and protease expression in lymph nodes / lymph node stroma cells and lung / lung fibroblasts. With few exceptions, ASML ${ }^{\mathrm{wt}}$ exosomes exerted the strongest effect, which we interpret in the sense that a major contribution of CD151 and Tspan8 might rely on facilitating binding and uptake. Notably, effects on protease and adhesion molecule expression were mostly stronger after in vivo application than after in vitro coculture. We consider in vivo cooperation between exosome target cells and the exosome modulated matrix as a likely explanation.

Expression of several chemokines and angiogenesisrelated factors and -receptors were significantly affected by $\mathrm{ASML}^{\mathrm{wt}}$ exosomes. Differences in the response to $\mathrm{ASML}^{\mathrm{wt}}$ versus $-\mathrm{CD} 151^{\mathrm{kd}}$, - Tspan $8^{\mathrm{kd}}$ and $-\mathrm{CD} 151 / \mathrm{Tspan}^{\mathrm{kd}}$ exosomes provided additional evidence for a selective engagement of exosomal CD151 in SDF1 upregulation and of exosomal Tspan8 in VEGFR2, VEGFR3 and CD31 upregulation. In cooperation with exosomal CD49d Tspan8 initiates overshooting angiogenesis [6769]. Instead, ASML ${ }^{\text {wt }}$ cells and exosomes, which do not express CD49d, selectively support lymphatic metastasis [70], fitting the upregulation of VEGFR3 [71]. Though many carcinoma metastasize via blood and lymphatic vessels, lymph nodes frequently are the first metastatic station [72]. Thus, the selective and efficient contribution of exosomal Tspan8 towards VEGFR3 induction deserves further studies to unravel the underlying mechanism, which may provide a hint towards therapeutic interference.

Tumor exosomes can be immunosuppressive [59], which frequently is accompanied by a shift towards immunosuppressive subpopulations like myeloid-derived suppressor cells and $\mathrm{T}_{\text {reg }}[11,58,59,73,74]$. We noted, an increase in the inflammatory cytokines TNF $\alpha$ and IL6 and the immunosuppressive cytokine IL10 [75-77], however without evidence for significantly impaired effector cytokine expression. This is surprising as FoxP3 became strongly upregulated in LNC cocultured with ASMLwt exosomesand [78]. In LNC and, more pronounced in $\mathrm{BMC} \mathrm{TFG} \beta$, a central regulator of immune response $[78,79]$, was upregulated. In line with this finding, ASML exosomes promoted JAK/Stat activation [7678]. The impact of exosomes on inflammatory cytokines and TGF $\beta$ being more pronounced in BMC, which very efficiently take up tumor exosomes, and being strongest after coculture with ASML ${ }^{\text {wt }}$, but hardly seen with poorly binding ASML-CD151/Tspan8 ${ }^{\mathrm{kd}}$ exosomes points towards exosomal CD151 and Tspan8 particularly contributing to exosome binding/uptake.

Taken together, tumor exosomes support induction of an inflammatory response and stroma cell activation. The engagement of exosomal CD151 and Tspan8 in inflammation mostly relies on facilitating binding and uptake. Instead, exosomal CD151 and/or Tspan8 have bearing on SDF1, CXCR4, VEGFR1 and, most relevant for lymphatic metastasis, VEGFR3 expression, such that a blockade of tetraspanins could well provide a therapeutic option. This consideration gains weight by the feedback of exosomes from metastasizing on non-metastatic tumor cells. 


\section{The contribution of exosomal CD151 and Tspan8 to epithelial mesenchymal transition}

Metastasizing tumor cells are supposed to present a subpopulation of CIC [80] and it has been argued that CIC transfer the potential to metastasize to non-metastatic tumor cells possibly via exosomes [81-83]. Thus, we finally controlled the impact of ASML ${ }^{\text {wt }}$ exosomes on ASML-CD151/Tspan $8^{\mathrm{kd}}$ cells. RTK expression remained unaltered except for VEGFR1 and VEGFR3. Expression being very low in ASML cells and exosomes excludes changes by coculture with ASML ${ }^{\text {wt }}$ exosomes to be due to direct protein transfer. The functional relevance of VEGFR expression in tumor cells as well as the pathway, whereby exosomes account for VEGFR expression, also seen in non-transformed host cells, remains to be explored. Lymphangiogenesis regulation is a complex process, which involves Ras, the MAPK cascade, PI3K/ Akt signaling, TGF $\beta$ and Notch [71], where our data point towards a special engagment of Notch.

In view of the partial overlap of (lymph)angiogenesis and EMT [84] and being aware that EMT is one of the first steps towards metastasis $[85,86]$, we evaluated EMT gene expression in ASML-CD151/Tspan ${ }^{\mathrm{kd}}$ cells after coculture with ASML ${ }^{\text {wt }}$ and for comparison -CD151 ${ }^{\mathrm{kd}}$ and $-\mathrm{Tspan} 8^{\mathrm{kd}}$ exosomes. ASML ${ }^{\mathrm{wt}}$ exosomes most strongly upregulated Notch. The intracellular domain of Notch binds to RBP-J $\mathrm{K}$ (recombination binding protein- $\mathrm{J} \kappa$ ), converting the repressor complex into an activator of Notch target gene transcription [87]. Thus, it is tempting to speculate that exosomal proteins and/or miRNA affect a central, upstream component in Notch signaling, as vimentin, Snail, Slug and Twist expression also became upregulated, though to a minor degree. Similar to the regulation of VEGFR3, the impact of ASML-Tspan 8 kd exosomes was weaker than that of ASML ${ }^{\mathrm{wt}}$ exosomes, which we interpret as indicating a contribution of exosomal tetraspanins, but also excluding the tetraspanins as exclusive mediators.

Thus, ASML ${ }^{\text {wt }}$ exosomes promote EMT in nonmetastatic cells. The striking impact of exosomal CD151 and Tspan8 demands for elucidating the underlying mechanism, where we presently cannot exclude a major contribution by tetraspanin-facilitated exosome binding and uptake. Despite this open question, induction of EMT by exosomes of a metastasizing tumor line in a nonmetastasizing tumor line strongly supports our hypothesis on the central importance of exosomal tetraspanins in promoting metastasis.

\section{CONCLUSION}

We here provide strong evidence for a central role of exosomal tetraspanins in metastasis. Exosomes facilitate motility and invasiveness by modulating the extracellular matrix, a process wherein exosomal CD151 and Tspan8 are directly engaged due to their associations with integrins and proteases. Exosomes also drive hematopoietic cells towards an inflammatory phenotype and initiate protease and chemokine / chemokine receptor expression in stroma cells. Most importantly, exosomes stimulate EMT in non-metastatic cells. CD151 and Tspan8 are essential for exosome-initiated target cell and non-CIC activation and reprogramming. It remains to be explores, whether the tetraspanin contribution is a sequel of the engagement in exosome binding and uptake or whether tetraspanins additionally contribute to the recruitment of signaling molecules and/or miRNA. Irrespective of this open question, a blockade of exosomal Tspan8 and CD151 appears most promising for interfering with metastasis.

\section{MATERIAL AND METHODS}

\section{Cell lines}

ASML [70], ASML-Tspan $8^{\mathrm{kd}}$, ASML-CD151 ${ }^{\mathrm{kd}}$ [51], ASML-CD151/Tspan8 ${ }^{\mathrm{kd}}$, LN332 secreting 804G [88], $\mathrm{LuFb}, \mathrm{LnStr}$ (B12) [89], RAEC lines were maintained in RPMI $1640 / 10 \% \mathrm{FCS}$, supplemented for ASMLTspan $8^{\mathrm{kd}}$ and ASML-CD151 ${ }^{\mathrm{kd}}$ cells with $750 \mu \mathrm{g} / \mathrm{ml} \mathrm{G} 418$ and for ASML-CD151/Tspan $8^{\mathrm{kd}}$ additionally with $5 \mu \mathrm{g} /$ $\mathrm{ml}$ puromycin. ASML-Tspan $8^{\mathrm{kd}}$ were transfected with pSuperGFP-neoplasmid containing CD151 shRNA to generate stable double knockdown lines (Primers: Tab.S1) (Qiagen, Hildesheim, Germany) following the supplier's suggestion.

\section{Antibodies}

see Tab.S2.

\section{Cell and tissue preparation}

The local tumor, draining lymph nodes, lung and bone marrow were collected. Single cell suspensions were obtained by pressing through fine gauze. Alternatively, organs were shock frozen or lysates were prepared by tissue disruption (UltraTurrax, 3-times, 30 sec on ice).

\section{Exosome preparation}

Cells were cultured (48h) in serum-free medium. Cleared supernatants $(2 \times 10 \mathrm{~min}, 500 \mathrm{~g}, 1 \times 20 \mathrm{~min}, 2000 \mathrm{~g}$, $1 \times 30 \mathrm{~min}, 10000 \mathrm{~g}$ ) were centrifuged $(90 \mathrm{~min}, 100000 \mathrm{~g}$ ) and washed (PBS, 90min, 100000g). The resuspended pellet was purified by sucrose gradient centrifugation. Where indicated, exosomes were $\mathrm{SP}-\mathrm{Dio}_{18}(3)$-labeled before sucrose gradient centrifugation and 2 washings [24]. 


\section{Sucrose density gradient centrifugation}

Cell lysates or exosomes in $2.5 \mathrm{M}$ sucrose were overlaid by a continuous sucrose gradient $(0.25 \mathrm{M}-2 \mathrm{M})$ and centrifuged $(15 \mathrm{~h}, 150000 \mathrm{~g})$, collecting twelve $1 \mathrm{ml}$ fractions.

Immunoprecipitation, Western blot: Lysates (HEPES buffer, $1 \%$ Lubrol or $1 \%$ Brij96, $1 \mathrm{mM}$ PMSF, protease inhibitor mix, $30 \mathrm{~min}, 4^{\circ} \mathrm{C}$ ) were immunoprecipitated, incubated with ProteinG-Sepharose (1h) and washed. Lysates/immunoprecipitates were resolved on $7-12 \%$ SDS-PAGE. After transfer, blocking, immunoblotting with primary and HRP-labeled Streptavidin or secondary antibodies, blots were developed with the ECL detection system.

Flow cytometry followed routine procedures. For intracellular staining, cells were fixed with $1 \%$ formalin and permeabilized $(0.5 \%$ Tween in PBS) in advance. Apoptosis was determined by AnnV/PI staining. Exosomes were incubated with $4 \mu \mathrm{m}$ aldehyde-sulfate latex-beads (Invitrogen, Karlsruhe, Germany), blocking free aldehyde groups (PBS/100mM glycine, $20 \mathrm{~min}, 20^{\circ} \mathrm{C}$ ) before staining. Staining was evaluated using a FACSCalibur and the Cell Quest program (BD, Heidelberg, Germany).

\section{Histology and immunofluorescence}

Snap frozen sections $(8 \mu \mathrm{m})$ were fixed with chloroform/aceton (1:1), 4min, dried and incubated with antibodies, washed, exposed to biotinylated secondary antibodies and alkaline phosphatase conjugated avidinbiotin solution, counter-staining sections with H\&E. Endogenous tissue alkaline phosphatase activity was ablated with levamisole solution and non-specific binding was blocked using an avidin-biotin blocking kit (Vector Laboratories, Burlingame, CA, USA). Immunofluorescence staining followed routine procedures. For intracellular staining cells were permeabilized with $0.1 \%$ Triton after fixation with $4 \%$ Formaldehyde. Slides were mounted in Elvanol to generate digitized images (Carl Zeiss LSM710 confocal microscope; software Carl Zeiss Axioview Rel. 4.6).

\section{Adhesion}

Cells were seeded on matrix protein-coated 96well F-bottom plates. After washing, adherent cells were stained with crystal-violet and lysed, evaluating OD595 photometrically. Adhesion is presented as the percentage of input cells.

\section{Migration}

Cells, in the upper part of a Boyden chamber (RPMI/0.1\%BSA), were separated from the lower part (RPMI $/ 20 \% \mathrm{FCS}$ ) by $8 \mu \mathrm{m}$ pore size polycarbonatemembranes. After $16 \mathrm{~h}$ the lower membrane side was stained (crystal-violet), measuring OD595 after lysis. For in vitro wound healing, a subconfluent monolayer was scratched with a pipette tip, following wound closure by light-microscopy. For video-microscopy, Hoechst 33342 stained cells $\left(5 \times 10^{4}\right)$ were seeded on matrix-coated 24-well plates. Plates were placed under an Olympus IX81 inverse microscope with a $\mathrm{Hg} / \mathrm{Xe}$ lamp, an incubation chamber $\left(37^{\circ} \mathrm{C}, 5 \% \mathrm{CO}_{2}\right)$, a CCD camera (Hamamatsu) and a ScanR acquisition soft ware (Olympus, Hamburg, Germany). Two pictures (20-fold magnification) / chamber (2ms exposure) were taken every $20 \mathrm{~min}$ for $12 \mathrm{~h}$. Migration was quantified according to Manual_tracking plugin running in the open-source software Image J.

\section{Invasion}

Polycarbonate membranes ( $8 \mu \mathrm{m}$ pore size) transwell permeable supports were coated with $100 \mu 1$ 1:5 diluted Matrigel and kept at $37^{\circ} \mathrm{C}$ in a humidified atmosphere overnight [55]. After washing, $5 \times 10^{4}$ cells in $200 \mu 1$ RPMI $/ 1 \%$ BSA were placed on the gels. The lower chamber contained RPMI with $20 \%$ FCS. After $48 \mathrm{~h}$ at $37^{\circ} \mathrm{C}, 5 \% \mathrm{CO}_{2}$, the medium in the insert was removed and cells not invading the gels were washed off. Matrix invasion and recovery on the lower membrane side was evaluated microscopically and photometrically after crystal-violet staining and lysis.

\section{Proliferation}

Cells $\left(2 \times 10^{4}\right)$ were seeded in F-bottom 96-well plates adding ${ }^{3} \mathrm{H}$-thymidine $(10 \mu \mathrm{Ci} / \mathrm{ml})$. ${ }^{3} \mathrm{H}$-thymidine incorporation was evaluated after $24 \mathrm{~h}$ ( $\beta$-counter). Alternatively, cells were CFSE (carboxy fluorescein succinimidyl ester)-labeled, determining CFSE dilution after $24 \mathrm{~h}, 48 \mathrm{~h}$ and $72 \mathrm{~h}$ by flow-cytometry.

Cell cycle progression was evaluated using PI staining and standard procedures.

\section{Apoptosis}

Cells $\left(1 \times 10^{5}\right)$ were grown for $48 \mathrm{~h}$ in RPMI $/ 10 \% \mathrm{FCS}$ containing cisplatin. Survival was monitored by annexinVAPC/PI staining and ${ }^{3} \mathrm{H}$-thymidine uptake. 


\section{Soft agar assay}

Tumor cells in $0.3 \%$ agar were seeded in 6-well plates on a preformed 1\% agar layer counting colonies after $3 \mathrm{wk}$.

\section{Zymography}

Conditioned medium $(\mathrm{CM})$ of starved cells $\left(1 \times 10^{6}\right)$ was centrifuged $(15 \mathrm{~min}, 15000 \mathrm{~g})$ and/or depleted of exosomes $\left(\mathrm{CM}^{-\mathrm{exo}}\right)$. Aliquots were incubated with Laemmli buffer $\left(15 \mathrm{~min}, 37^{\circ} \mathrm{C}\right)$ and separated in a $10 \%$ acrylamide gel containing $1 \mathrm{mg} / \mathrm{ml}$ gelatin. After $3 \mathrm{x}$ washing $(2.5 \%$ Triton), gels were incubated in developing buffer $(50 \mathrm{mM}$ Tris, $10 \mathrm{mM} \mathrm{CaCl}_{2}, 150 \mathrm{mM} \mathrm{NaCl}, 2 \mu \mathrm{M} \mathrm{ZnCl}_{2}, \mathrm{pH} 7.5$ ) $\left(37^{\circ} \mathrm{C}, 48 \mathrm{~h}\right)$ and stained with Coomassie-blue.

\section{In vivo assays}

BDX rats received $1 \times 10^{6}$ tumor cells, ifp. Where indicated, rats received concomitantly and repeated in 3 day intervals $200 \mu \mathrm{g}$ exosomes ifp. The local growth, growth in the popliteal and the inguinal lymph node were evaluated weekly with sliding calipers. Animals were sacrificed at the indicated time points or when draining nodes reached $2 \mathrm{~cm}$ diameter, upon $>10 \%$ weight loss, short breathing and a stiff thorax due to lung metastases or latest after $120 \mathrm{~d}$. For the evaluation of exosome distribution, rats received $200 \mu \mathrm{g}$ dye-labeled exosomes, iv or ifp. Animals were sacrificed at the indicated time points. They were bled by heart puncture and all lymphatic / hematopoietic organs were excised and analyzed by flow cytometry for the presence of labeled cells. Animal experiments were Government-approved (Baden-Wuerttemberg, Germany).

\section{Statistical analysis}

Assays were repeated at least 3 times. P-values $<0.05$ (two-tailed Student's t-test, Anova) were considered significant.

\section{Authorship}

SY, WM and UE performed and analyzed experiments, MZ planned and analyzed experiments and wrote the manuscript.

\section{ACKNOWLEDGEMENTS}

This investigation was supported by the Deutsche Krebshilfe and the Wilhelm-Sander Stiftung (MZ). We cordially thank Angela Frank for help with animal experiments and immunohistology.

\section{Conflict of Interest Disclosure}

The authors declare that they have no competing interests.

\section{Abbreviations}

CIC: cancer initiating cells, CM: conditioned medium, coll: collagen, EMT: epithelial-mesenchymal transition, FN: fibronectin, HA: hyaluronic acid, ifp: intrafootpad, iv: intravenously, kd: knockdown, LN: lymph node, LN111/LN332: laminin111/laminin332, LnStr: LN stroma line, LuFb: lung fibroblasts, RAEC; rat endothelial cell line, RTK: receptor tyrosine kinase, TEM: tetraspanin-enriched microdomain, wt: wild type.

\section{REFERENCES}

1. Sales KM, Winslet MC, Seifalian AM. Stem cells and cancer: an overview. Stem Cell Rev. 2007; 3: 249-255.

2. Chen SY, Huang YC, Liu SP, Tsai FJ, Shyu WC, Lin SZ. An overview of concepts for cancer stem cells. Cell Transplant. 2011; 20: 113-120.

3. Visvader JE. Cells of origin in cancer. Nature. 2011; 469: 314-322.

4 Chaffer CL, Weinberg RA. A perspective on cancer cell metastasis. Science 2011; 331: 1559-1564.

5. Kaplan RN, Rafii S, Lyden D. Preparing the "soil": the premetastatic niche. Cancer Res. 2006; 66: 11089-11093.

6. Scadden DT. Nice neighborhood: emerging concepts of the stem cell niche. Cell 2014; 157: 41-50.

7. Sleeman JP, Christofori G, Fodde R, Collard JG, Berx G, Decraene C, Rüegg C. Concepts of metastasis in flux: the stromal progression model. Semin Cancer Biol. 2012; 22: 174-186.

8. Brabletz T. EMT and MET in metastasis: where are the cancer stem cells? Cancer Cell. 2012; 22: 699-701

9. Thuma F, Zöller M. Outsmart tumor exosomes to steal the cancer initiating cell its niche. Semin Cancer Biol. 2014; 28C: $39-50$.

10. Peinado H, Lavotshkin S, Lyden D. The secreted factors responsible for pre-metastatic niche formation: old sayings and new thoughts. Semin Cancer Biol. 2011; 21: 139-146.

11. Sceneay J, Smyth MJ, Möller A. The pre-metastatic niche: finding common ground. Cancer Metastasis Rev. 2013; 32: 449-464.

12. Fevrier B, Raposo G. Exosomes: endosomal-derived vesicles shipping extracellular messages. Curr Opin Cell Biol. 2004; 16: 415-421.

13. Mathivanan S, Ji H, Simpson RJ. Exosomes: extracellular organelles important in intercellular communication. J Proteomics. 2010; 73: 1907-1920.

14. Yoon YJ, Kim OY, Gho YS. Extracellular vesicles as 
emerging intercellular communicasomes. BMB Rep. 2014 Aug 8. pii: 2914. [Epub ahead of print]

15. Saleem SN, Abdel-Mageed AB. Tumor-derived exosomes in oncogenic reprogramming and cancer progression. Cell Mol Life Sci. 2014 Aug 26. [Epub ahead of print]

16. Vlassov AV, Magdaleno S, Setterquist R, Conrad R. Exosomes: Current knowledge of their composition, biological functions, and diagnostic and therapeutic potentials. Biochim Biophys Acta. 2012; 1820: 940-948.

17. Petersen KE, Manangon E, Hood JL, Wickline SA, Fernandez DP, Johnson WP, Gale BK. A review of exosome separation techniques and characterization of B16-F10 mouse melanoma exosomes with AF4-UVMALS-DLS-TEM. Anal Bioanal Chem. 2014 Aug 2. [Epub ahead of print]

18. Fontana S, Saieva L, Taverna S, Alessandro R. Contribution of proteomics to understanding the role of tumor-derived exosomes in cancer progression: state of the art and new perspectives. Proteomics. 2013; 13: 1581-1594.

19. Kowal J, Tkach M, Théry C. Biogenesis and secretion of exosomes. Curr Opin Cell Biol. 2014; 29C: 116-125.

20. Hemler ME. Tetraspanin functions and associated microdomains. Nat Rev Mol Cell Biol. 2005; 6: 801-811.

21. Yáñez-Mó M, Barreiro O, Gordon-Alonso M, Sala-Valdés M, Sánchez-Madrid F. Tetraspanin-enriched microdomains: a functional unit in cell plasma membranes. Trends Cell Biol. 2009; 19: 434-446.

22. Pols MS, Klumperman J. Trafficking and function of the tetraspanin CD63. Exp Cell Res. 2009; 315: 1584-1592.

23. Berditchevski F, Odintsova E. Tetraspanins as regulators of protein trafficking. Traffic. 2007; 8: 89-96.

24. Rana S, Claas C, Kretz CC, Nazarenko I, Zöller M. Activation-induced internalization differs for the tetraspanins CD9 and Tspan8: Impact on tumor cell motility. Int J Biochem Cell Biol. 2011; 43: 106-119.

25. Zöller M. Tetraspanins: push and pull in suppressing and promoting metastasis. Nat Rev Cancer. 2009; 9: 40-55.

26. Hemler ME. Tetraspanin proteins promote multiple cancer stages. Nat Rev Cancer. 2014; 14: 49-60.

27. Wang H, Rana S, Giese N, Büchler MW, Zöller M. Tspan8, CD44v6 and alpha6beta4 are biomarkers of migrating pancreatic cancer-initiating cells. Int J Cancer. 2013; 133: 416-426.

28. Valadi H, Ekström K, Bossios A, Sjöstrand M, Lee JJ, Lötvall JO. Exosome-mediated transfer of mRNAs and microRNAs is a novel mechanism of genetic exchange between cells. Nat Cell Biol. 2007; 9: 654-659.

29. Lee TH, D'Asti E, Magnus N, Al-Newadi K, Meehan B, Rak J. Microvesicles as mediators of intercellular communication in cancer--the emerging science of cellular 'debris'. Semin Immunopathol. 2011; 33: 455-467.

30. Inal JM, Kosgodage U, Azam S, Stratton D, Antwi-Baffour S, Lange S. Blood/plasma secretome and microvesicles. Biochim Biophys Acta. 2013;1834: 2317-2325.
31. Zheng X, Chen F, Zhang J, Zhang Q, Lin J. Exosome Analysis: A Promising Biomarker System with Special Attention to Saliva. J Membr Biol. 2014 Aug 19. [Epub ahead of print]

32. Rana S, Yue S, Stadel D, Zöller M. Toward tailored exosomes: the exosomal tetraspanin web contributes to target cell selection. Int J Biochem Cell Biol. 2012; 44: 1574-1584.

33. Charrin S, le Naour F, Silvie O, Milhiet PE, Boucheix C, Rubinstein E. Lateral organization of membrane proteins: tetraspanins spin their web. Biochem J. 2009; 420: 133-154.

34. Levy S, Shoham T. The tetraspanin web modulates immune-signalling complexes. Nat Rev Immunol. 2005; 5: 136-148.

35. Berditchevski F. Complexes of tetraspanins with integrins: more than meets the eye. J Cell Sci. 2001; 114: 4143-4151.

36. Hasegawa M, Furuya M, Kasuya Y, Nishiyama M, Sugiura T, Nikaido T, Momota Y, Ichinose M, Kimura S. CD151 dynamics in carcinoma-stroma interaction: integrin expression, adhesion strength and proteolytic activity. Lab Invest. 2007; 87: 882-892.

37. Wang HX, Li Q, Sharma C, Knoblich K, Hemler ME. Tetraspanin protein contributions to cancer. Biochem Soc Trans. 2011; 39: 547-552.

38. Greco C, Bralet MP, Ailane N, Dubart-Kupperschmitt A, Rubinstein E, Le Naour F, Boucheix C. E-cadherin/p120catenin and tetraspanin Co-029 cooperate for cell motility control in human colon carcinoma. Cancer Res. 2010; 70: 7674-7683.

39. Guo Q, Xia B, Zhang F, Richardson MM, Li M, Zhang JS, Chen F, Zhang XA. Tetraspanin CO-029 inhibits colorectal cancer cell movement by deregulating cell-matrix and cellcell adhesions. PLoS One. 2012; 7: e38464.

40. Berthier-Vergnes $\mathrm{O}$, Kharbili ME, de la Fouchardière A, Pointecouteau T, Verrando P, Wierinckx A, Lachuer J, Le Naour F, Lamartine J. Gene expression profiles of human melanoma cells with different invasive potential reveal TSPAN8 as a novel mediator of invasion. Br J Cancer. 2011; 104: 155-165.

41. Gustafson-Wagner E, Stipp CS. The CD9/CD81 tetraspanin complex and tetraspanin CD151 regulate $\alpha 3 \beta 1$ integrindependent tumor cell behaviors by overlapping but distinct mechanisms. PLoS One. 2013; 8: e61834.

42. Sterk LM, Geuijen CA, van den Berg JG, Claessen N, Weening JJ, Sonnenberg A. Association of the tetraspanin CD151 with the laminin-binding integrins alpha3beta1, alpha6beta1, alpha6beta4 and alpha7beta1 in cells in culture and in vivo. J Cell Sci. 2002; 115: 1161-1173.

43. Liu L, He B, Liu WM, Zhou D, Cox JV, Zhang XA. Tetraspanin CD151 promotes cell migration by regulating integrin trafficking. J Biol Chem. 2007; 282: 31631-31642.

44. Zijlstra A, Lewis J, Degryse B Stuhlmann H, Quigley JP. The inhibition of tumor cell intravasation and subsequent metastasis via regulation of in vivo tumor cell motility by 
the tetraspanin CD151. Cancer Cell. 2008; 13: 221-234.

45. Hong IK, Jeoung DI, Ha KS, Kim YM, Lee H. Tetraspanin CD151 stimulates adhesion-dependent activation of Ras, Rac, and $\mathrm{Cdc} 42$ by facilitating molecular association between[beta]1 integrins and small GTPases. J Biol Chem. 2012; 287: 32027-32039.

46. Yáñez-Mó M, Gutiérrez-López MD, Cabañas C. Functional interplay between tetraspanins and proteases. Cell Mol Life Sci. 2011; 68: 3323-3335.

47. Shi GM, Ke AW, Zhou J, Wang XY, Xu Y, Ding ZB, Devbhandari RP, Huang XY, Qiu SJ, Shi YH, Dai Z, Yang XR, Yang GH, Fan J. CD151 modulates expression of matrix metalloproteinase 9 and promotes neoangiogenesis and progression of hepatocellular carcinoma. Hepatology. 2010; 52: 183-196.

48. Shiomi T, Inoki I, Kataoka F, Ohtsuka T, Hashimoto G, Nemori R, Okada Y. Pericellular activation of proMMP-7 (promatrilysin-1) through interaction with CD151. Lab Invest. 2005; 85: 1489-1506.

49. Yañez-Mó M, Barreiro O, Gonzalo P, Batista A, Megías D, Genís L, Sachs N, Sala-Valdés M, Alonso MA, Montoya MC, Sonnenberg A, Arroyo AG, Sánchez-Madrid F. MT1-MMP collagenolytic activity is regulated through association with tetraspanin CD151 in primary endothelial cells. Blood. 2008; 112: 3217-3226.

50. Rao Malla R, Gopinath S, Alapati K, Gorantla B, Gondi CS, Rao JS. Knockdown of cathepsin B and UPAR inhibits CD151 and $\alpha 3 \beta 1$ integrin-mediated cell adhesion and invasion in glioma. Mol Carcinog. 2012; 52: 777-790.

51. Yue S, Mu W, Zöller M. Tspan8 and CD151 promote metastasis by distinct mechanisms. Eur J Cancer. 2013; 49: 2934-2948.

52. Zech D, Rana S, Büchler MW, Zöller M. Tumor-exosomes and leukocyte activation: an ambivalent crosstalk. Cell Commun Signal. 2012; 10: 37.

53. Herlevsen M, Schmidt DS, Miyazaki K, Zöller M. The association of the tetraspanin D6.1A with the alpha6beta4 integrin supports cell motility and liver metastasis formation. J Cell Sci. 2003; 116: 4373-4390.

54. Gesierich S, Paret C, Hildebrand D, Weitz J, Zgraggen K, Schmitz-Winnenthal FH, Horejsi V, Yoshie O, Herlyn D, Ashman LK, Zöller M. Colocalization of the tetraspanins, CO-029 and CD151, with integrins in human pancreatic adenocarcinoma: impact on cell motility. Clin Cancer Res. 2005; 11: 2840-2852.

55. Mu W, Rana S, Zöller M. Tumor-derived exosomes and the matrix. Neoplasia. 2013; 15: 875-887.

56. Zhang HG, Grizzle WE. Exosomes: a novel pathway of local and distant intercellular communication that facilitates the growth and metastasis of neoplastic lesions. Am J Pathol. 2014; 184: 28-41.

57. Jung T, Castellana D, Klingbeil P, Cuesta Hernández I, Vitacolonna M, Orlicky DJ, Roffler SR, Brodt P, Zöller M. CD44v6 dependence of premetastatic niche preparation by exosomes. Neoplasia. 2009; 11: 1093-1105.

58. Peinado H, Alečković M, Lavotshkin S, Matei I, CostaSilva B, Moreno-Bueno G, Hergueta-Redondo M, Williams C, García-Santos G, Ghajar C, Nitadori-Hoshino A, Hoffman C, Badal K, Garcia BA, Callahan MK, Yuan J, Martins VR, Skog J, Kaplan RN, Brady MS, Wolchok JD, Chapman PB, Kang Y, Bromberg J, Lyden D. Melanoma exosomes educate bone marrow progenitor cells toward a pro-metastatic phenotype through MET. Nat Med. 2012; 18: 883-891.

59. Whiteside TL. Immune modulation of T-cell and NK (natural killer) cell activities by TEXs (tumour-derived exosomes). Biochem Soc Trans. 2013; 41: 245-251.

60. Filipazzi P, Bürdek M, Villa A, Rivoltini L, Huber $\mathrm{V}$. Recent advances on the role of tumor exosomes in immunosuppression and disease progression. Semin Cancer Biol. 2012; 22: 342-349.

61. Zhang HG, Zhuang X, Sun D, Liu Y, Xiang X, Grizzle WE. Exosomes and immune surveillance of neoplastic lesions: a review. Biotech Histochem. 2012; 87: 161-168.

62. Bussolati B, Dekel B, Azzarone B, Camussi G. Human renal cancer stem cells. Cancer Lett. 2013; 338: 141-146.

63. Rana S, Malinowska K, Zöller M. Exosomal tumor microRNA modulates premetastatic organ cells. Neoplasia. 2013; 15: 281-295.

64. Sarvaiya PJ, Guo D, Ulasov I, Gabikian P, Lesniak MS. Chemokines in tumor progression and metastasis. Oncotarget. 2013; 4: 2171-2185.

65. Altevogt P, Bretz NP, Ridinger J, Utikal J, Umansky V. Novel insights into exosome-induced, tumor-associated inflammation and immunomodulation. Semin Cancer Biol. 2014; 28: 51-57.

66. Lakkaraju A, Rodriguez-Boulan E. Itinerant exosomes: emerging roles in cell and tissue polarity. Trends Cell Biol. 2008; 18: 199-209.

67. Nazarenko I, S, Baumann A,McAlear J, Hellwig A, Trendelenburg M, Lochnit G, Preissner KT, Zöller M. Cell surface tetraspanin Tspan8 contributes to molecular pathways of exosome-induced endothelial cell activation. Cancer Res. 2010; 70: 1668-1678.

68. Claas C, Seiter S, Claas A, Savelyeva L, Schwab M, Zöller M. Association between the rat homologue of CO029, a metastasis-associated tetraspanin molecule and consumption coagulopathy. J Cell Biol. 1998; 141: 267280 .

69. Gesierich S, Berezovskiy I, Ryschich E, Zöller M. Systemic induction of the angiogenesis switch by the tetraspanin D6.1A/CO-029. Cancer Res. 2006; 66: 7083-7094.

70. Matzku S, Komitowski D, Mildenberger M, Zöller M. Characterization of BSp73, a spontaneous rat tumor and its in vivo selected variants showing different metastasizing capacities. Invasion Metastasis. 1983; 3: 109-123.

71. Coso S, Bovay E, Petrova TV. Pressing the right buttons: signaling in lymphangiogenesis. Blood. 2014; 123: 2614- 
2624.

72. Alitalo A, Detmar M. Interaction of tumor cells and lymphatic vessels in cancer progression. Oncogene. 2012; 31: 4499-4508.

73. Xiang X, Poliakov A, Liu C, Liu Y, Deng ZB, Wang J, Cheng Z, Shah SV, Wang GJ, Zhang L, Grizzle WE, Mobley J, Zhang HG. Induction of myeloid-derived suppressor cells by tumor exosomes. Int J Cancer. 2009; 124: 2621-2633.

74. Liu Y, Xiang X, Zhuang X, Zhang S, Liu C, Cheng Z, Michalek S, Grizzle W, Zhang HG. Contribution of MyD88 to the tumor exosome-mediated induction of myeloid derived suppressor cells. Am J Pathol. 2010; 176: 24902499.

75. Bretz NP, Ridinger J, Rupp AK, Rimbach K, Keller S, Rupp C, Marmé F, Umansky L, Umansky V, Eigenbrod T, Sammar M, Altevogt P. Body fluid exosomes promote secretion of inflammatory cytokines in monocytic cells via Toll-like receptor signaling. J Biol Chem. 2013; 288: 36691-36702.

76. Zhou D, Huang C, Lin Z, Zhan S, Kong L, Fang C, Li J. Macrophage polarization and function with emphasis on the evolving roles of coordinated regulation of cellular signaling pathways. Cell Signal. 2014; 26: 192-197.

77. Chow A, Zhou W, Liu L, Fong MY, Champer J, Van Haute D, Chin AR, Ren X, Gugiu BG, Meng Z, Huang W, Ngo V, Kortylewski M, Wang SE. Macrophage immunomodulation by breast cancer-derived exosomes requires Toll-like receptor 2-mediated activation of NF-кB. Sci Rep. 2014; 4: 5750.

78. Robbins PD, Morelli AE. Regulation of immune responses by extracellular vesicles. Nat Rev Immunol. 2014; 14: 195208.

79. Worthington JJ, Fenton TM, Czajkowska BI, Klementowicz JE, Travis MA. Regulation of TGF $\beta$ in the immune system: an emerging role for integrins and dendritic cells. Immunobiology. 2012; 217: 1259-1265.

80. Dorado J, Lonardo E, Miranda-Lorenzo I, Heeschen C. Pancreatic cancer stem cells: new insights and perspectives. J Gastroenterol. 2011; 46: 966-973.

81. Quesenberry PJ, Aliotta JM. Cellular phenotype switching and microvesicles. Adv Drug Deliv Rev. 2010; 62: 11411148.

82. Gu J, Qian H, Shen L, Zhang X, Zhu W, Huang L, Yan Y, Mao F, Zhao C, Shi Y, Xu W. Gastric cancer exosomes trigger differentiation of umbilical cord derived mesenchymal stem cells to carcinoma-associated fibroblasts through TGF- $\beta$ /Smad pathway. PLoS One. 2012; 7: e52465.

83. Munoz JL, Bliss SA, Greco SJ, Ramkissoon SH, Ligon KL, Rameshwar P. Delivery of Functional Anti-miR-9 by Mesenchymal Stem Cell-derived Exosomes to Glioblastoma Multiforme Cells Conferred Chemosensitivity. Mol Ther Nucleic Acids. 2013; 2: e126.

84. Schaal C, Pillai S, Chellappan SP. The Rb-E2F transcriptional regulatory pathway in tumor angiogenesis and metastasis. Adv Cancer Res. 2014; 121: 147-182.

85. Brabletz S, Schmalhofer O, Brabletz T. Gastrointestinal stem cells in development and cancer. J Pathol. 2009; 217 : 307-317.

86. Karamitopoulou E. Tumor budding cells, cancer stem cells and epithelial-mesenchymal transition-type cells in pancreatic cancer. Front Oncol. 2013; 2: 209.

87. Yamamoto S, Schulze KL, Bellen HJ. Introduction to Notch signaling. Methods Mol Biol. 2014; 1187: 1-14.

88. Homma Y, Ozono S, Numata I, Seidenfeld J, Oyasu R. alpha-Difluoromethylornithine inhibits cell growth stimulated by a tumor-promoting rat urinary fraction. Carcinogenesis. 1985; 6: 159-161.

89. LeBedis C, Chen K, Fallavollita L, Boutros T, Brodt P. Peripheral lymph node stromal cells can promote growth and tumorigenicity of breast carcinoma cells through the release of IGF-I and EGF. Int J Cancer. 2002; 100: 2-8. 